Monday 23 May 1994

\title{
Plenary Session
}

Anpirinaris

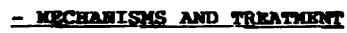

Anaphylaxis may occur following exposure to diverse range of antigenic stimuli by 1njection, ingestion or bite. The parenteral administration of antibiotics and other substances, and nuts are comson causes.

Classically, antigens that trigger anaphylaxis bind to IgR antibodiea attached to the cell membranes of Interstitial mast cells and circulating basophils, activating the release of
potent modiators, including histamine, which product the signs
and symptoms of anaphylaxis. Host reactions cannot be predicted and develop within minutes of exposure to the precipitating cause.

The first symptom which usually occurs is litching of the palms of the hands and the soles of the feet. This should be considered the red 11 ght symptom and should alert the clinician that immediate actlon my be required. Urticaxia common life-threatening clinical feature; bronchospasa is the most difficult to troat. Anglo-oedene and pulmonary oedenn can 11 so occur. It is widely recognised that anaphylexis is moxe common in individuals on beta-blockers and that these
individuals are of ten refractory to treatment.

The cornerstones of management of anaphylaxis are early recognition, removal of the cause, oxygenation and adrenaline as the drug of choice $\lambda$ suitable inltial dosage of

adrenaline is $0.5 \mathrm{ml} 1: 1,000$ for an adult, $0.1 \mathrm{ml} / \mathrm{kg} 1: 10,000$ for a child, preferably by the lntramuscular or subcutaneous may aiso bo of value.

While in most cases this will suffice, in up to 53 of cases more drastic therapeutic intervention 18 required. In these situations, following a fluid bolus repeated doses of intravenous adronaline may need to be given, and a more aggrossive approach my need to be adopted in the use of H noradrenaline should be used.

In addition to these management considerations, safe clinical practice also involves reducing the risk of recurrence. It is vital that the causative agent is identified and that the presentation and response to treatment is accurately

do alloxise inexed prepared to treat themselves. 


\section{Track A}

A1

Intra-Osseous route is a well recognised technique for the resuscitation of children. This presentation describes its use not only for the resuscitation of three children but also for the induction of anaesthesia required for cerebral protection in these children.

Case 1 was a six week old boy with a severe head injury and extreme hypovolaemia Resuscitation was carried out through a right tibial intra-osseous line and anaesthesia induced with suxamethonium and midazolam. This was seen to act within 45 seconds as was atropine given for a bradycardia precipitated during intubation. Blood was transfused through an improvised blcod warmer consisting of a bowl of water at a measured $40^{\circ}$ centigrade with a length of fine bore extension tubing running through this from the manually driven syringe to the intra-osseous needle. This appeared to be an effective method for warming fluids administered via this route.

Case 2 was a hypoxic 18 month old boy with convulsions unresponsive to rectal diazepam. Anaesthesia was induced through a left tibial intra-osseous line with thiopentone and suxamethonium prior to transfer of the child to the Intensive Care Unit.

\section{Case 3 was a 10 month old girl with a severe head injury and hypovolaemia.} Anaesthesia was induced through a right tibial intra-osseous line using thiopentone and suxamethonium.

The above cases all demonstrate that when necessary it is possible to induce anaesthesia through the intra-osseous route. The drugs appear to act as rapidly as by the intravenous route and did not cause any apparent local complications. The fluid warmer is simple, cheap and quick to set up. Slides will be shown of Case 1 with the intra-osseous line in situ along with the blood warmer in use

A 4 Ketamine Assisted Intubation for Adult Patients in Status Asthmaticus: A Prospective Case Study

Jeffrey Schaider, MD, FACEP

Brenda Hayakawa, MD, FAAP, FRCPC

1900 West Polk Street; Dept of Emergency Medicine; 1Oth Floor; Chicago, Illinois 60612 . USA

Study objective: To determine the emcacy of betumine a discociative anesthetic and analgesic agent with

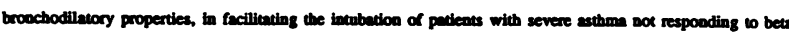

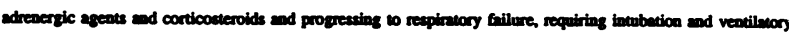
expore

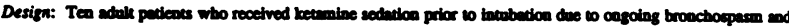

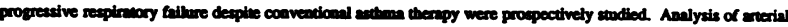

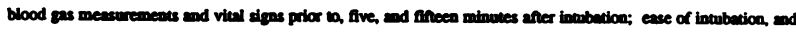
semi prestification of ond socretions were underticen. Seting: Lerge munictpel hoeptial emergency deperment.

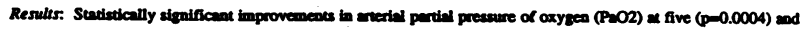

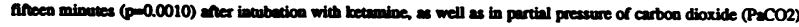

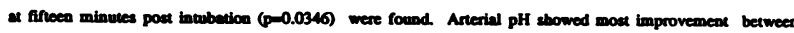

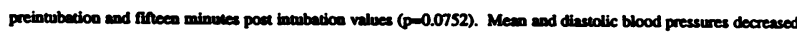

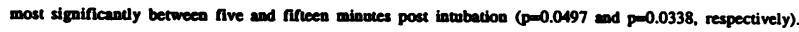

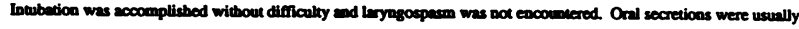
minimall, with oaly two cases requiring suction during intubation. No patient experienced complications from intubations. No pedient experiencod disturbing dreams.

Conclusions. Ketamine is a sefe and effective agent to use in patients with status aschmaticus and respiratory failure requiring intubation.

Ketamine; Intubation; Asthma
A5 The use of continuous positive airway pressure (CPAP) by face-mask in the emergency department management of severe acute cardiogenic pulmonary oedema.

\section{A. Kambourakis, Registrar, Emergency Department \& G. Duke, Depury Director of ¿nacsthesia \& Intensive Care, Preston \& Northcote Community Hospital, 205 Bell Stroet Preston. Victoria 3072 A ustralia}

Acutc cardiogenic pulmonary oodema is a common admission diagnosis in the emergency department. While most patients respoed to conventienal therapy, thooe with sevise hypuria and acidosis usually require respiratory support. Recent data suggest thent the carly use of non-invasive respiratory support with continuous positive airway pressure (CPAP) administered by face-mask can reduce the neod for intubation and mochanical ventilation ${ }^{1}$ and reduce inlensive care unit stay and hospital consts ${ }^{2}$.

The purpose of this study was to document the usc of facc-mask CPAP for scvere acute cardiogenic pulmonary oedema in the emcrgency department, including the incidenoc of complications. The methodology involved a prospective study of all patients prescnting 10 the emergency departmeal in scvere acule candiogenic pulmonary oedema between April 1992 and December 1993 and recciving CPAP by facc-mask. CPAP was commenced in the emergency department in all cases, and the patients were all subsequently adminced to the intensive carc/high dependency unit Mean blood pressure, hearl rate, respiratory rate, arterial pH, artcrial $\mathrm{PCO}_{2}$, arterial $\mathrm{pO}_{2}, \mathrm{PaO}_{2} / \mathrm{FiO}_{2}$ ratio and haemoglobin oxygen sanuration $\left(\mathrm{SaO}_{2}\right)$ were compared at presentation and after 30 minutcs of CPAP therapy.

Comparison was also undertaken with a historical control group of similar patients during the 18 month period prior $w$ the introdaction of face-mask CPAP in the emergency department of this hospital.

These results, to be presented and discussed, indicate that facc-mask CPAP can be safcly wilised in the emergency department with beneficial therapcutic effect

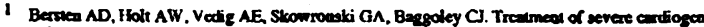

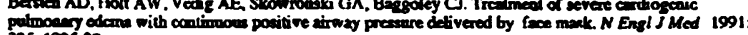
325: 182530

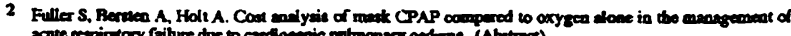

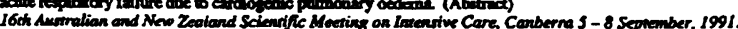

A6 Computer stimulation model of emergency department overcrowding: predicting optimal public policy

Emergency department overcrowding has become a pressing issue as health care reform is debated in the United states. Recent studies by the U.S. General Accounting Office have confirmed that growth in American emergency department (ED) visits can be attributed to the uninsured, elderly patients, and more seriously ill patients. Almost half of ED users resent with non-urgent conditions. Many have no primary care providers. Medicare and Medicaid patients represent about 37\% of ED patient volume.

Prior research by Mehl (1993, paper presented at Southern Medical association) showed that patient presenting with non-urgent conditions to the emergency department to do so for reasons that are very rational to them including convenience, availability of free parking, availability of childcare at home, and perceived speed of being seen. A lack of primary care physician or a conception of why one would want a primary care physician was common in this study as well.

The author resents a systems dynamics computer simulation model for emergency department use and overcrowding which tracks the flow of patients through the emergency department with shunts for flow of patients into other care areas. The model analyzes a variety of solutions which have been proposed to alleviate emergency department overcrowding in terms of probability of success and cost effectiveness. It is made available to health planners to use as desired. 

A7 EMERGENCY DEPARTMENT SCREENING OF CHEST PAIN PATIENTS UTILIZING ELECTRON
BEAM TOMOGRAPHY SCANIING

Study objective: To determine whether electron beam tomography (EBT) scans (also called ultra-fast or cine Cr scans) can be used by Emergency Department (ED) physicians to screen patients for admission who have a good history for new onset angina, no prior history of coronary artery disease and a normal electrocardiogram and cardiac enzymes.

Design: A pilot study of 10 admitted patients, ages 31-64, meeting the above-mentioned criteria. EBT scanning for coronary calcification was performed in addition to a staff cardiologist-directed evaluation for coronary ischemia. Results of the two modalities were compared. Setting: Large tertiary care hospital with 65,000 annual ED visits. Results: of the 10 studied patients, 6 were noted tio have some coronary calcification on EBT scan. Of these 6 patients, 4 had moderate and 2 had minimal calcifications. Three of the 6 had significant coronary disease on angiography requiring atherectomy or angioplasty. The other 3 had a normal Dobutamine stress echo (1), a normal treadmill exercise test (1) and a normal exercise thallium scan (1). Four patients had no EBT evidence of coronary calcification. of these, none had evidence or coronary disease or ischemia on angiography (1), exercise thallium scan (2) or echocardiography (1).

Conclusion: Although further evaluation of this new imaging modality is necessary, EBT scanning may be a cost-saving and effective tool for triaging EO patients with possible new unstable coronary ischemia and normal ED screening tests.
A8 Coding clinical information - the new Read Clinical Terms Jonathan Marrow

Accident \& Emergency Department, Arrowe Park Hospital, Upton, Wirral, Merseyside L49 SPE

In 1982, Dr James Read, a family doctor in a market town in Leicestershire, England, devised a system of coding to ease entry of clinical information into his practice computer records system. Augmented over the years, his system is used extensively in family practices in the United Kingdom still and in many hospitals now, as well. Although widely accepted, the original Read Codes have important limitations. Trauma cannot always be well describod. Terms relating to poisoning are confusing. There is little possibility for expression of severity or doubt in diagnosis.

The National Health Service Management Executive commissioned the Clinical Terms Project further to develop the Read Clinical Codes. The main Project ran between April 1992 and April 1994, with tcams from each of 43 medical specialities working to bring the thesaurus of Ternis up to date in their particular field. Areas of overlap have had to be agreed. We have also tried to bring the Terms into line with other clinical classifications now in use. Mapping to ICD-9 has been obligatory and to ICD-10 also, once this comes into use.

I shall decribe some of the major issues which have been raised by workers in the Project in general and also problems encountered by the Working Group in Accident \& Emergency Medicine. I shall give examples of solutions, where wc belicve that we found them, and explain the constraints which prevented us making all the improvements we would have liked.

Although the Clinical Terms Project is up to its deadline, a continuing mechanism for maintainance and devclopment is being scl up, both to make good inevitable ommissions and to allow expression of new ideas. 


\section{Track B}

B1

Continuous vs. Intermittent High Dose Nebulized Albuterol in Children with a Severe Exacerbation of Asthma

In an effort to define the most efficacious Emergency Department therapy for acute severe exacerbations of asthma, twenty-five 7 to 17 year old children experiencing severe asthma attacks were randomly assigned to receive either continuous (10 mg over 1 hour) or two intermittent ( $5 \mathrm{mg} 30$ minutes apart) treatment of nebulized Albuterol. Both groups received an oral loading dose of $2 \mathrm{mg} / \mathrm{kg}$ (maximum $60 \mathrm{mg}$ ) of Prednisolone before nebulization was begun.

Both groups showed a similar clinical response to therapy with an improved clinical asthma score and an equivalent improvement in peak expiratory flow rate (PEFR). Neither group experienced significant side effects from therapy. High dose intermittent nebulized Albuterol is as effective in treating severe exacerbations of asthma in children as the more expensive and time consuming continuous nebulized treatment.
B2

Peaching Rmergency Paediatrics - LPIS ("TK) B.M. Phillipe

Booth Hall Children's Bospital, Charlestom Road, Manchester M9 2MA.

Ldvanced Paodiatric Life support Course in the U.K.

1. Origin - the philosophy, derelopment and future

direction of the teaching course will be discussed.

2. Educational aims - educational techniques will

be described.

3. Content - a brief synopsis will be made of course content.

4. Outcome - the results of research on the retention and development of akills and knowledge in candidates who have completed such a course will be presented.

B5

Psychological Support after an Accident to a Child

Dr Sara Levene, MA, MRCP

Child Accident Prevention Trust, 18 - 20 Farringdon Lane, London ECIR 3AU

Immediate treatment for physical injuries is available throughout the UK. However, when a child is injured or killed in an accident, there is also psychological trauma to the patient, their family and their friends. This may be expressed with various degrees of severity, including post traumatic stress disorder. The availability of immediate support and advice is patchy, and depends on the geographical area and the nature of the injury.

This paper will describe:

- some of the manifestations of post traumatic stress disorder in childhood.

These include sleep disturbance, clinginess, poor performance at school and impaired relationships with peers.

- some of the response mechanisms available in the UK

These include dedicated teams of staff on call to deal with any sudden death in the Accident and Emergency Department, charities advising on the sequelae of specific injuries such as the Spinal injuries Association, and self help groups such as The Compassionate Friends (for bereaved parents).

- "emotional first aid" - advice that could be given to parents at an early stage to help them minimise the psychological effects of injury to their child. This includes advice on debriefing the child soon after the accident (critical incident stress debriefing).

A model for a coordinated UK response to this problem will also be described. This involves reviewing existing provision, deriving models of good practice which could form the basis for training and improved provision in other settings, and a mechanism for networking existing support workers.

CHILDREN, POST TRAUMATIC STRESS DISORDER

B6

Is $\mathrm{Sa} 02$ a valid measure of well-being in the critically ill?

\section{R G Mitchell, C E Robertson} Abstract:

Department of Accident \& Emergency Medicine, Royal Infirmary, Edinburgh

Objectives:

To determine the value of peripheral $\mathrm{SaO} 2$ measurement in critically ill and injured patients. Study Desian:

Prospective study of all patients admitted to the Resuscitation Room. Measurement of peripheral oxygen saturation $\left(\mathrm{S}_{2} \mathrm{O} 2\right)$, pulse rate, non-invasive and invasive blood pressure and simultaneous measurement

of arterial blood gas tensions.

Setting:

University teaching hospital Accident and Emergency Department.

Patients:

200 consecutive patients triaged to the Resuscitation Room with life-threatening medical, surgical or trauma presentations.

Results:

No correlation was demonstrated between heart rate, systolic or diastolic blood pressure and $\mathrm{SaO} 2$ measurement. $15 \%$ of patients had significant desaturation $(\mathrm{SaO} 2<90 \%)$, but $42 \%$ of these had a $\mathrm{PaO} 2>10 \mathrm{kPa}$. There was no correlation between $\mathrm{PaCO} 2$ and $\mathrm{SaO} 2.16 \%$ of patients had a

$\mathrm{PaCO} 2>9 \mathrm{kPa}$, however of these only $28 \%$ had a corresponding abnormality on $\mathrm{SaO} 2$ measurement. In the sub-group of patients with indwelling intra-arterial lines, blond pressure was monitored simultaneously via a pressure transducer and a standard sphygmomanometer cuff, a good correlation was found in both systolic and diastolic pressures( $r=0.88$ and 0.95 respectively).

Conclusions:

Peripheral oxygen saturation measurement is a poor guide to the severity of physiological disturbance in critically ill patients, and correlates poorly with other commonly used parameters. In particular patients with respiratory dysfunction and hypercapnoea may have misleadingly 'normal' $\mathrm{SaO2}$ values that can he misconstrued as indicating well-being.

Pulse oximetrv. Haemodynamics. Criticallv ill patients. 
Background: The shock index $(\mathrm{SI}$ - heart rate/systolic blood pressure, normal range 0.5-0.7) is related to left ventricular mochanical performance' and is helpful in the evaluation and therapy of shock.

Hypothesis: SI is useful for triage, disposition and allocation of level of care for patients presenting to the emergency department (ED).

Study design: Prospective sample

Setting: Urban hospital ED

Patients: Consecutive 275 adult presenting to an ED for urgent medical care. Patients < 18yrs, pregnant or in cardiopulmonary arrest were excluded.

Interventions: Vital signs, SI and triage priority (II, II) on presentation, disposition from ED and admission to Intensive Care Unit (ICU).

Results:

\begin{tabular}{|c|c|c|}
\hline & $\begin{array}{l}\text { Group } \mid(S \mid>0.9) \\
n=41\end{array}$ & $\begin{array}{l}\text { Group II(S) }<0.9) \\
n=234\end{array}$ \\
\hline Age(yrs) & $47(18)$ & $53(20)$ \\
\hline Templ( $\left.{ }^{\circ} \mathrm{C}\right)$ & $37.5(1)$ & $37(1)$ \\
\hline RR(pm) & $21(1)$ & 2011) \\
\hline HR(bpm) & $104(17)^{*}$ & $82(12)^{\circ}$ \\
\hline $\operatorname{SBP}(m m H g)$ & $113(15)^{\circ}$ & $140(27)$ \\
\hline$D B P(m m H g)$ & $70(11)$ & $82(14)$ \\
\hline Si & $1.0(0.3)^{*}$ & $0.610 .1)$ \\
\hline Triage(Priority I) & $23^{*}$ & 45 \\
\hline Admission(total) & $35^{\circ}$ & 105 \\
\hline ICU & $10^{*}$ & 13 \\
\hline
\end{tabular}

Values are mean(SD), $p<0.01$ (T-test), $+p<0.001$ (Chi-square test), group I vs II.

Conclusion: With apparently normal vital signs in group $1, \mathrm{SI}>0.9$ indicated severe illness requiring immediate resuscitation and intensive monitoring and therapy upon admission. $\mathrm{Sl}$ is a better variable than vital signs commonly measured in the ED for triage and disposition in acute critical illness. 1) Rady et al . Resuscitation, 1992;23:227

2) Rady et al. Am J Emerg Med, 1992;10:538
B9

Trauma Team Organisaton

A.F. T. Brown; C. T. Myers

Emergency Department, Royal Brisbane Hospital, Brisbane Qld 4029, Australia TRAUMA TEAM ORGANISATION

Trauma systems based on trauma centres have become the gold standard for trauma care in North America. However, the epidemiology of trauma in the UK and Australasia is significantly different. A major component of the success of the best American trauma systems lies in organisation. BY contrast, many hospitals in the UK and Australasia still have no organised response to trauma and where trauma teams do exist, they are often ad hoc and disorganised. The absence of a defined team leader and precise task allocation leads to confusion and delay even when individual team members are highly skilled.

This paper will describe a trauma team approach to overcome these problems, which could be utilised by any hospital using existing staff and resources. Task priority and allocation, trauma team size. trauma team leader and activation criteria will be discussed.

A trauma team approach was introduced in the Emergency Department of the Royal Brisbane Hospital. Laminated action cards detail precise task allocation to four doctor nurse pairs working simultaneously. Equipment, procedures, pathology requests, radiology and clerical duties were standardised in advance. An audit form was completed after each resuscitation. In an initial review, one hundred and eight patients admitted with trauma met criteria for activation of the trauma team. Time of arrival to completion of initial resuscitation was reduced by 63 per cent and time in the department by 51 per cent.

There is ongoing research into the best system of trauma care in the UK and Australasia but unti convincing results are available, adoption of a trauma team approach by all hospitals receiving major trauma would be appropriate.

Major trauma; Trauma teams; Trauma systems.
Failure to recognise blood loss contributes to some preventable deaths following injury. This reflects shortcomings in the assessment of haemorrhaging patients: blood pressure (BP) does not fall until blood loss is severe as it is protected by the baroreflex, whilst changes in heart rate (HR) can be biphasic. Allgower has suggested that shock index (SI= HR/ systolic BP) may be a more sensitive indicator. However, this depends largely on the patient's reflex response to the haemorrhage. An alternative parameter, which is less dependent on reflex responses is stroke volume, which should fall early in haemorrhage (Starling's Law of the Heart). This can be assessed non invasively as stroke distance (SD) using ultrasound. The aim of the present study was to determine the effect of a progressive "haemorrhage" on BP, HR, SI and SD.

Progressive "haemorrhage" was mimicked in 8 young healthy volunteers (21-40yrs) using lower body negative pressure (LBNP) to pool blood in the lower body. LBNP was applied progressively at 17.5, -3.5 and $-50 \mathrm{mmHg}$, each step being held for $20 \mathrm{~min}$, and the parameters recorded after steady states have been attained during the last $10 \mathrm{~min}$ of each step. The effectiveness of LBNP was monitored by recording central venous pressure (CVP).

CVP fell significantly (P<0.05, repeated measures analysis of variance) with each step of LBNP from a control level of $4.8 \pm 0.6 \mathrm{mmHg}$ to $-0.8 \pm 0.7 \mathrm{mmHg}$ (mean \pm SEM, LBNP - $50 \mathrm{mmHg}$ ). During this time mean BP did not change significantly from the control level of $88 \pm 3 \mathrm{mmHg}$. HR and $\mathrm{SI}$ did not change at the first level of LBNP, but increased progressively thereafter from control levels of $61 \pm 3$ beats. $\min ^{-1}$ and $0.50 \pm 0.02$ beats. $\mathrm{min}^{-1} \mathrm{mmHg}^{-1}$ to $77 \pm 6$ beats. $\mathrm{min}^{-1}$ and $0.66 \pm 0.05$ beats. $\mathrm{min}^{-1} \mathrm{mmHg}^{-1}$ respectively. HR fell markedly in two individuals when they become presyncopal, while SI either continued to rise or fell slightly. SD fell significantly at each step of LBNP from a control level of $24.8 \pm 1.7$ to $12.5 \pm 1.3 \mathrm{~cm}$ (LBNP -50mmHg).

These results indicate that while BP is of little use in the early detection of blood loss and HR can be misleading in some individuals. SI and especially SD may be better indicators.
B10

\section{SHOOTINGS AND STABBINGS}

Preston and Northcote Community Hospital and the Alfred Hospital are situated in Melboume, a major Australian city with a population of 3.5 million. The emergency departments of both these hospitals receive a large amount of penetrating trauma which includes stabbings and shootings.

In a pilot study of all stabbing and shooting patients admitted to PANCH from September 1990 to August 1991, the circumstances surrounding the incident, type of wèapon used, injuries sustained, management and patient outcome were examined. The major findings of tbis study were :

- The incidence of stabbing was significantly higher than shooting.

- Most of the circumstances surounding the injuries were not incidental.

- Stabbing injuries were mainly to the abdomen and the chest and were more serious than shooting injuries.

- Most patients were young adult males

This current study has been expanded at PANCH until August 1993. From September 1992 to August 1993, a parallel study has been conducted at the Alfred hospital, a major referral centre which houses the only Trauma Centre in Mebourne.

Injuries have been retrospectively scored using the Injury Severity Score and the Revised Trauma Score to evaluate the severity of the injury, and toprodict patient outcome.

The results of these studies and analysis of the trauma scoring will be presented 


\section{Track C}

C1

THE USE OF MAGNESIUM IN THE EMERGENCY DEPARTMENT

Magnesium activates over 300 enzyme systems, playing an essential role regulating many celluar functions, particularly those involved in energy metabolism. Magnesium deficiency is common in acutely ill patients although clinical features of hypomagnesaemia are nonspecific and often missed. At risk patients include zlcoholics, those on diuretics, those with diabetic ketoacidosis and in severe malnutrition. Conversely, hypermagnesaemia is rare other than in renal failure, and is often iatrogenic with the early signs of toxicity being hypotension, bradycardia, hyporeflexia and lethargy.

The therapeutic use of magnesium ranges from well validated to anecdotal. Cardiac uses include atrial and ventricular arrhythmias, particularly torsade de pointes and in digoxin toxiciry. It may also reduce mortality following acute myocardial infarction. Respiratory use includes acute asthma, although the optimum dosage and efficacy are in doubt. Obstetric uses include as a tocolytic and for pre-eclampsia where its probable action is to reverse cerebral vasoconstriction rather than any direct anticonvulsant activity. Miscellaneous uses include for delirium tremens, unresponsive hypokalaemia and hypocalcaemia, and as an antacid or cathartic.

Fractical problems with its use are the varying concentrations and salts available, the confusion with dosages cited in grams, milligrams, millimols and milliequivalents, and the relevance and availability of a serum level. This paper will review current viewpoints on the role of magnesium and the evidence to support its safe use in the Emergency Department.

C2 Shock

Background: Elevated plasma $\mathbf{M g}^{++}$is a risk factor for trauma patients. Hemorrhage, leading to tissue ischemia, hypoxia and acidosis, releases $\mathrm{Mg}^{++}$into plasma from intracellular stores. The factors causing this release are unknown. We examined the combined effect of hypoxia and acidosis, independent of hypovolemia, on plasma $\mathrm{Mg}^{++}$levels.

Methods: Pentobarbital anaesthetized pigs $(n=5)$ were intubated, ventilated with room air, and instrumented with Swan Ganz, arterial and venous catheters. We created bilateral pneumothoraces and progressively reduced alveolar ventilation. Cardiovascular status was monitored continuously. Blood gases and plasma $\mathrm{Mg}^{++}$levels wivere sampled at 30 minute intervals. " "* indicates value significantly different from control (ANOVA, Tukey's, $p<0.05$ ).

Results: After 180 minutes of progressive respiratory compromise, mixed venous (MV) PO2 decreased from $37.94 \pm 2.18$ to $22.12 \pm 2.23^{\circ}$, MV PCO2 increased from $45.49 \pm 2.99$ to $75.00 \pm 3.03^{\circ}$, and $\mathrm{MV} \mathrm{pH}$ decreased from $7.37 \pm 0.02$ to $7.06 \pm 0.02^{\circ}$. Cardiac output and arterial pressure remained constant. This combination of hypoxia and acidosis increased $\mathbf{M g}^{{ }^{+*}}$ levels from $16.05 \pm 0.39$ to $23.44 \pm 1.34^{\circ}$. Our previous data show that, in pigs with acidosis alone (bilateral pneumothoraces with supplemental 02) or hypoxia alone (hydroxylamine poisoning of $\mathrm{Hb}), \mathrm{Mg}^{++}$levels did not change.

Conclusion: It is the combination of hypoxia and acidosis that increases plasma $\mathrm{Mg}^{++}$in hemorrhagic shock.
C3 OBSERYER BLIND COMPARISON OF SINGLE DOSE KV. TNTECTION QF TENOXICAM AND PETHIDINE FOR ACUTE RENAL COLIC.

\author{
A PLOT STUDY - C. CURRY, AM. KELLY
}

OBECTIVE: To compare the anaigesic efficacy of single dose intravenous (IV) To compare the analgesic efficacy of single dose intravenous (IV)
tenoxicam $40 \mathrm{mg}$ with pethidine $75 \mathrm{mg}$ in patients with renal colic.

DESIGN AND SETIING:

Prospective, randomized, ohserver blins study of $\mathbf{4 0}$ adult paticnts presenting to the Emergency Department of Christchurch Hospital, Christchureh, New Zealand with y clinical diagnosis of renal colic.

METHOD:

After an initial dose of metoclopramide $10 \mathrm{mg}$ IV, paticnts were randomized into two groups. Onc reccived tenoxicann $40 \mathrm{mg}$ IV and the other pethidinc 75mg IV. Pain was quantified using visual analoguc pain scalcs with measurements being taken bcfore treaument and at 10,20,30 and 120 minutes after administration of the study drug. Requircments for additional doses of pethidinc and the occurrenoc of adverse events were also reconded.

RESULTS:

Both tenoxicam $40 \mathrm{mg}$ and pethidine $75 \mathrm{mg}$ resulted in statistically significant reductions in pein scores at 30 mimutes $(p<0,01)$. Nu
statistically significant difference between the analgesic efficiency or statistically significant difference between the analgesic efficiency of
the drugs was detocted. There was a trend towards mure rapid the drugs was detocted. There was a trend towards mure rapid
onset of analgesia in the pethidine trealed gruup. The groups did onset of analgesia in the pethidine trealed group. The groups did
not differ in requircments for additional pethidine or in the occursence of adverse effexts.

CONCLUSION: Tennxicam may be a suitable alternative to pcthidino for l.V. analgesia in renal conlic. C4 Evaluation of sheep as a potential large animal model for

Study of the pathogenesis of Ioxic Shock Syndrome (ISS) has been hampered by the absence of a comprehensive large animal model.

Study Objective: Evaluation of the sheep as a potential animal model for rss.

Design: Twelve awake adult female sheep were infected with $10 \mathrm{ug} / \mathrm{kg}$ of Toxic Shock Synd. Toxin - 1 (TSST-1).

Interventions: Animals were instrumented with pulm. artery, CVP and aortic catheters. After a stable baseline perlod and full recovery from anesthesia, the infusion of TSST-1 was given. Bemodynamic measurements, blood chemistries and cell counts were performed at baseline and up to 24 brs. Iater. Animals were also observed for clinical signs of rss: Results: Values are mean $\pm \operatorname{SEM}\left(\star^{\mathrm{p}} \mathrm{p}<0.05\right.$ Students $t$-test)

\begin{tabular}{|c|c|c|c|c|}
\hline & Base & $1 \mathrm{hr}$ & $4 \mathrm{hr}$ & $8 \mathrm{hr}$. \\
\hline & $\begin{array}{l}\overline{90+6} \\
5 . \overline{9}+4\end{array}$ & $\begin{array}{l}77+10 \\
4.7 \pm+6 *\end{array}$ & $\begin{array}{l}71+8 \star \\
4.5+.6 \star\end{array}$ & $\begin{array}{l}82+8 \\
6 . \overline{0}+.7\end{array}$ \\
\hline & $58 \pm \overline{3}$ & $33+\overline{3} *$ & $27+\overline{4} \star$ & $39+6 *$ \\
\hline pa & $13 \mp 1$ & $26 \pm 3 *$ & $23 \mp 2 *$ & $20 \pm 2 *$ \\
\hline VR & $1280 \pm 70$ & $15 \overline{8} 0 \pm 150 *$ & $15 \overline{7} 0 \pm 160 *$ & $11 \overline{50} \pm 150$ \\
\hline
\end{tabular}

All animals rapidly developed clinical and laboratory evidence of multisystem dysfunction consistent with diagnostic criteria of ISS. Hemodynamic derangements were generally resolved by $8-12 \mathrm{hrs}$.

Conclusions: The sheep appears to be an effective comprehensive large animal model for the study of TSS. The role of TSST-1 as a principal causative toxin in TSS is further supported. 
Track D

D1 Does active decompresion improve the haemodynamic state during CPR

\section{U.M.Guly, C.E. Robertson}

Accident \& Emergency Department, Royal Infirmary of Edinburgh, Lauriston Place, Edinburgh EH3 9YW

Patients following out of hospital cardiac arrest were studied during mechanical CPR using a thumper and active compression decompression $\mathrm{CPR}$ using an $\mathrm{ACD}$ device, in 3 minute cycles. End-tidal $\mathrm{CO} 2$ (ETCO2), which reflects cardiac output during CPR, intrarterial pressure monitoring and central venous blood gas analysis were used to assess the effectiveness of CPR.

RESULTS.

1. End-tidal CO2.

22 patients were studied using ETCO2. Ventilation using a mechanical ventilator remained unchanged. The mean ETCO2 rose significantly on changing from mechanical to $A C D$ CPR and fell on returning to mechanical CPR, suggesting an improved cardiac output with active decompression.

Mean ETCO2

\begin{tabular}{|c|c|c|c|}
\hline $\begin{array}{l}\text { Mechanical CPR } \\
1.1 \\
\text { ACD }\end{array}$ & $\begin{array}{l}\text { ACD } \\
1.81 \\
\text { Mechanical CPR }\end{array}$ & $\begin{array}{c}\text { Number } \\
21\end{array}$ & $\begin{array}{l}\text { P } \\
0.007\end{array}$ \\
\hline 1.93 & 1.08 & 20 & 0.016 \\
\hline
\end{tabular}

2. Arterial Pressure monitoring through a femoral arterial line was performed in 7 patients. The systolic pressure attained with the $\mathrm{ACD}$ was significantly greater than that with mechanical $\mathrm{CPR}$ but there was no difference in the diastolic pressures. The shape of the arterial pressure waveform differed between the two techniques.

\begin{tabular}{|lllll|}
\hline Arterial pressures & Mechanical CPR & ACD & Number & p \\
Mean systolic pressure & 55.6 & 103.6 & 7 & $\mathbf{0 . 0 1 8}$ \\
Mean diastolic pressure & 35.1 & 35.1 & 7 & - \\
\hline
\end{tabular}

3. Central venous blood gas analysis was performed in 7 patients during both mechanical and ACD CPR. There was a trend towards increasing acidosis throughout the resuscitation and an increase in central venous $\mathrm{PO} 2$ with the ACD compared with thumper CPR but these did not attain statistical significance. CONCLUSIONS.

Active decompression resulted in greater systolic blood pressure and ETCO2 than mechanical CPR. This suggests that the cardiac output and hence perfusion is greater using the $\mathrm{ACD}$ than with mechanical CPR.

CPR. ACD. End-tidal C02. Systolic pressure

D2 Non pharmacological methods of terminating supraventricular tachycardia in the emergency

V. Lim Swee Han, V. Anantharaman, W. S. Teo, Arthur Tan

Accident \& Emergency Department, Department of Cardiology, Singapore General Hospital

Non-pharmacological methods have been shown to be effective in terminating acute onset supraventricular tachycardia (SVT). The efficancy of various vagal manoeuvres like carotid sinus massage (CSM) and Valsalva manoeuver (VM) in terminating spontaneous SVT in the Emergency Department has not been studied. We sought to compare the success of CSM with VM.

A prospective study was done for all patients (pts) who presented to our Emergency Department with SVT. They were randomised to undergo CSM or VM first. Those pts who underwent CSM were also randomised to left and right CSM first. The VM was performed by blowing against a sphygnomanometer to achieve an airway pressure of at least $\mathbf{4 0} \mathbf{m m H g}$ for a duration of 30 seconds or more. A total of 72 cases were seen from 1 May 1993 to 31 January 1994. All cases were tried with the non pharmacological technique of conversion. First 43 cases underwent VM first, with 9 (20.9\%) cases successfully converted to sinus rhythm. 4 cases were successfully converted to sinus rhythm by right CSM after failed VM. 29 cases underwent CSM first, with 18 having right CSM first and 11 left CSM first. 2 cases were converted to sinus rhythm with left CSM after failed right CSM. I case was converted to sinus rhythm with right CSM after failed left CSM. 3 cases were converted to sinus rhythm with VM after failing both right and left CSMs. In total, nonpharmacological methods were effective in terminating $26.4 \%$ of SVT ( 19 success out of 72 SVTs). VM appear to be superior to CSM. Overall successful rate of VM was 17.4\% (12 success out of 69 SVTs) and CSM was $11.1 \%$ ( 7 success out of 63 SVTs). The mean age for patients with successful VM is 38.9 years old \pm 16.6 years. The mean age for patient with successful CSM is $68+7.7$ years. $(\mathrm{P}<0.001)$

In conclusion, non pharmacological method can be attempted in the initial treatment of SVT as it is efficacious in about $1 / 4$ of pts. In younger age group VM is more efficacious than CSM.
D3

The Effect of St-91 on Hemodynamics During CPR

Adrenergic agonists are used in CPR to augment aortic diastolic pressure (AODP) and coronary perfusion pressure (CPP). Of the two classes of adrenergic agonists, phenethylamines and imidazolines, only phenethylamines, e.g. epinephrine, have been studied in CPR. Our hypothesis is that imidazolines that are active on the peripheral vasculature will be effective during CPR. The purpose of this study was to examine the imidazoline, St-91, on hemodynamics during CPR.

Six swine weighing 20.5 \pm 2.1 were instrumented for continuous hemodynamic measurements. Following 10 mins of ventricular fibrillation, CPR was begun. Following 3 mins of CPR the animals were allocated to receive either $0.2 \mathrm{mg} / \mathrm{Kg}$ or 2.0 $\mathrm{mg} / \mathrm{Kg}$ of St-91. Pressures were compared using a paired Stydent t-test (two-tailed). Statistical significance was considered at $P \leq 0.05$.

The AODP and CPP in $\mathrm{mm} \mathrm{Hg}$ are displayed below:

$\begin{array}{lrrr}\text { AODP } & \frac{\text { CPR }}{16.4 \pm 6.6} & \frac{\text { CPR }+0.2}{34.4 \pm 10.5} & \frac{P \text {-value }}{0.05} \\ \text { CPP } & 8.5 \pm 5.3 & 23.3 \pm 11.0 & 0.10 \\ & \text { CPR } & \text { CPR+2.0 } & \frac{\text { P-value }}{0.08} \\ \text { AODP } & 11.3 \pm 5.3 & 29.1 \pm 14.4 & 0.11\end{array}$

St-91 improved hemodynamics during CPR. Imidazolines provide a new therapeutic class of adrenergic agonists for evaluation during CPR.

D4 Defibrillation Burns - Cause, Treatment and Prevention

G. W. McNaughton, J. P. Wyatt, J. Byme

Department of Accident \& Emergency Medicine, Western Infirmary, Glasgow Gll 6NT

Introduction - Skin burns are accepted to be a complication of defibrillation. However there is no published data on their frequency, cause and treatment.

Objective - To assess the relative frequency of defibrillation burns in coronary care units and identify the possible factors contributing to their occurrence. Treatments prescribed in coronary care units were also noted.

Design - Postal questionnaire survey to Senior Sister / Charge Nurse.

Setting - United Kingdom, including Isle of Man and The Channel Islands.

Subjects - All 263 coronary care units as listed in the Directory of Emergency and Special Care Units 1993.

Results - 232 Replies were received (88.2\%). Defibrillation burns were seen in $98.7 \%$ of $\mathrm{CCU}$ 's, the majority having seen less than five burns during the preceding twelve months. Ten contributory factors were proposed. These included recurrent defibrillation in 196 replies $(84.5 \%)$, failure to use conductive pads or gel in $96(41.4 \%)$, failure to change conductive pads in $37(15.9 \%$ ), poor technique in 27 (11.6\%), inadequate paddle pressure in $24(10.3 \%$ ), use of gel in $19(8.2 \%)$, high energy defibrillation in $8(3.4 \%)$, small conductive pads in 8 (3.4\%), hairy chests in $4(1.7 \%)$, and fair skin in $2(0.8 \%)$. Topical treatments were prescribed in $96.1 \%$ of units and oral analgesia in $52.1 \%$. The most frequently prescribed topical treatment was $1 \%$ silver sulphadiazine cream (FLAMAZINE( ) ) in $78 \%$ of CCU's. Other commonly prescribed treatments were topical corticosteroid and topical local anaesthetic.

Conclusions - Defibrillation burns are relatively common in coronary care units. Many result from recurrent defibrillation and may be unavoidable in the patient undergoing prolonged resuscitation. However there are several identifiable factors which, if avoided, may lead to a reduction in the number of burns seen. Treatment with $1 \%$ silver sulphadiazine is the treatment favoured in the majority of Coronary Care Units.

DEFIBRILLATION BURNS 
Transesophageal rapid atrial stimulation for the treatment supraventricular tachycardias - preliminary results

Study objectives: To evaluate the efectivity of transesophageal rapid atrial stimulation (TAS) in the treatment of supraventricular tachycardia (SVT).

Design: prospective study.

Setting: University hospital departent of Emergency Medicine.

Participants: Adult patients with SVT

Interventions: Cardioversion with TAS was performed with the GALIX(1) (Instrumentacion Biomedica S.R.L., Argentinia).

The stimulations were performed with a frequency from $200 \mathrm{bpm}$ to $500 \mathrm{bpm}$.

Results:

Underlying disease, anthythmia and result of TAS

\begin{tabular}{cccc}
\hline Patient & underlying disease & anthythmia & result of stimulation \\
\hline 1 & history of myocarditis & atrial flutter & atrial fibrillation \\
2 & coronary heart disease & $S V T$ with 2:1 AV-block & atrial fibrillation \\
3 & congestive cardiomyopathy & $S V T$ with 2:1 AV-block & sinus mythm \\
4 & coronary heart disease & $S V T$ with 2:1 AV-block & atrial fibrilation \\
5 & aortic valve replacement & $S V T$ with 2:1 AV-block & atrial fibrillation* \\
6 & coronary heart disease & $S V T$ with 2:1 AV-block & sinus mythm \\
7 & coronary heart disease & $S V T$ with 2:1 AV-block & atrial fibrillation \\
\hline
\end{tabular}

- sinus rhythm achived 5 minutes after stimulation

Conclusions: TAS showed a high effectivity, easy and safe non invasive handling with

no need for anesthesia, and the possibility of instantaneous pacing.

$$
\text { H R GULY }
$$

Accident \& Beergency Dept Derriford Hopital Plymouth PL6 8DH

A I B departments should andit their diagnostic errors. Some errors are trivial but others an be life-threatening and so it 18 important to have an indication of the seriousness of an error. Some studies have divided errors into significant and non-significant but this is often very subjective and does not differentiate between various degrees of ignificance.

This paper describes a simple method of indicating the severity of a diagnostic error in an injured patient on scale of 1 to 10 . This uses a conbination of an matcoical measure of injury severity (the AIS) with a scale indicating the difference between the treatment wich should have been given to the patient and the treationt actually recelved by the patient. The validation of this scale is described and demonstrates wide variability in $A$ \& $B$ consultants' perception of the severity of errors.

The use of the scale in measuring the severity of diagnostic errors ade in one department over a six month period is also described.

Keymords: Audit and diagnostic error
D8

Do patients wait for the doctor or does the doctor walk for the patients?

\section{K. Y. Tham, P. W. Richmond, R. L. Evan}

The Accident Unit, Cardiff Royal Infirmary, Newport Road, Cardiff CE2 ISZ, Wales Abstract:

Objective To investigate the amount of time an average Accident \& Emergency department (A\&E) senior house officer apends on various clinical activitios while on duty

Desten The activition of 4 A\&E conior house officen (SHO)) of avenage apeed were monitored (by KIT) with a atopwatch. All shifts were studied, including weekenda. The A\&E department at Cardiff Royal Infirmary soes 77129 new cases per annum and 13520 review canes. The departmont has $12 \mathrm{SHO}$.

Reants 96.1 houn were analyood. The SHOn opent $77.9 \%$ of their time working. $5.7 \%$ of time having breaks and

meab while $16.4 \%$ of time there was no pationt in the department. 316 pationts were seen during the total working time

of 74.9 hours which meent that 4.2 petiento were soon per working hour.

Table 1 shows the time noeded to aceass and treat oech patioat in the differeat work areas.

\begin{tabular}{|c|c|c|c|c|c|}
\hline & Resucciation & Trolloy & Walling wounded & Paediatric & Average \\
\hline Minuees per pationt & 56 & 27.3 & 10.4 & 10.6 & 14.2 \\
\hline \multicolumn{6}{|c|}{ Table 2 shows the percontage of working time apont on varioun activition. } \\
\hline \multicolumn{5}{|l|}{ Chinical Activition } & \% working time \\
\hline \multicolumn{5}{|l|}{ I. Phyocician tank } & 81.5 \\
\hline \multicolumn{5}{|c|}{ 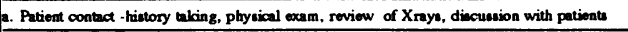 } & 39.7 \\
\hline \multicolumn{5}{|l|}{ b. Note kooping } & 18.7 \\
\hline \multicolumn{5}{|c|}{ e. Practical procedures } & 3.4 \\
\hline \multicolumn{5}{|c|}{ d. Refornals and telephone consulations } & 4.7 \\
\hline \multicolumn{5}{|c|}{ 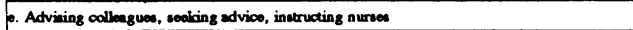 } & 4.6 \\
\hline \multicolumn{5}{|c|}{ 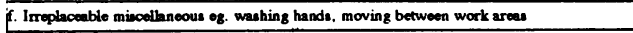 } & 10.4 \\
\hline \multicolumn{5}{|c|}{ II. Non-phyoician taels og. photoctating notes, venepuncture, filling in forme } & 18.5 \\
\hline
\end{tabular}

II. Non-phycician tacks og. photoctating notes, venepuncture, filling in forme

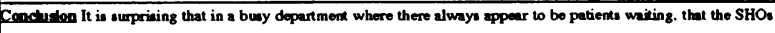
pend $16.4 \%$ of their time waiting for work. 18.3\% of their time could unef ully be given to other ataff with ponable

pudgeting savings, assuming this dose nod simply add to the time they are already doing nothing. Simple modifirations to

arious work areas and omployment of a doctor's aseistant and/or phlebotomitt might holp to reduce the amount of non. physician tanks.

time and motion study, average A\&E department SHO, physician tasks non-physician tasks, replaceable activities

SCALP CLOSURE WITH A NEW SYNTHETIC ABSORBABLE SUTURE

$$
\text { J D KELLY S C IANDON S I IRMIN }
$$

BELFAST CIIY HOSPIIAL, LISBURN ROAD, BELFASI BI9 7AB

Irradiated polyglactin 910 ("Vicryl Rapide") is a new rapidly absorbable synthetic polymer. It handles well, knots securely and is absorbed with minimal tissue reaction. Desuture is not required as the sutures fall out after 14 days. We wished to establish whether irradiated polyglactin 910 could replace monofilament polyanide in scalp wound closure. One hundred and nineteen patients presenting at a casualty department with scalp lacerations were randomised for suture with polyglactin 910 ( $n=63)$ or conventional non-absorbable monofilament polyamide ("Ethilon") ( $n=56$ ) as a control. The length, widest point and depth of injury were recorded. Wounds were classified according to the type of injury. Patients were assessed at 14 days and 3 months. Attendance at three months was poor (32\%) and thus analysis at this time is limited. There were no wound infections recorded. No wounds in either group showed evidence of erytheas or stitch abscess. At 14 days in the irradiated polyglactin 910 group there was no residual suture material in $66 \%$ of wounds. These were simply removed by wiping with gauze. Standard polyglactin 910 ("Vicryl) is too slowly absorbed for interrupted skin closure. Catgut stimulates an intense tissue reaction of ten causing stitch abscesses and its absorption is affected by adverse healing conditions. Wylon and surgical clips require desuture. There is a need for a rapidly absorbed non-reactive skin suture. Irradiated polyglactin 910 appears to fill this gap. The material supports skin for about a week, falls out at two wecks and stimulates ainimal tissue reaction. It is ideal for scalp suture and review for desuture is not necessary. Sutures; Suture techniqūes; 
D10 Patients with Psychosocial Problems in an ED Observation Unit

Objective: To examine the management in an emergency department (ED) observation unit (obs unit) of patients (pts) with psychosocial problems.

Design: Retrospective chart review of all pts managed in the ED obs unit of a university-affiliated community teaching hospital during 1988-1990.

Results: 685 of 7,024 pts (9.8\%) observed during the study period presented to the ED for psychosocial problems: $51 \%$ substance abuse (SA), $34 \%$ depression (D), $13 \%$ thought disorder (TD), $1 \%$ anxiety (A), $1 \%$ behavioral problem (B). The most common SA was alcohol (96\%); $15 \%$ of these pts had another problem (40\% head injury, 30\% laceration, $22 \%$ fracture). $59 \%$ of $\mathrm{D}$ pts presented with suicide attempt (70\% overdose, $19 \%$ self laceration, $5 \%$ hanging, $2 \%$ car accident, $1 \%$ jump from window) and $11 \%$ with suicide threat (39\% self laceration, $31 \%$ gunshot, $12 \%$ jump from window, $8 \%$ overdose). TD pts had hallucinations (74\%), paranoia (10\%), depression (5\%), mania (3\%), violent behavior (3\%), or catatonic state (2\%). $91 \%$ of pts were discharge without hospitalization after a mean 14.2 hrs observation (100\% SA, A, and B; $89 \%$ D; $62 \%$ TD).

Conclusion: Patients with serious psychosocial problems are managed in ED obs units with most avoiding hospitalization. 


\section{Tuesday 24 May 1994}

\section{Plenary Session}

"Care of Walk in Emergencies: Review of Recent Research"

Management of SVT

Dr Paul Preisz

Supra-ventrleuiar tachycardia is a common arrhythmia requiring treatment by Emergency physicians. The pathophysiology of this condition is briefly outlined and the treatment modalities and pharnacotherapy revieweo.

The physiology of caicium channels is considered in detail and in particular is related to the cinical use of caicium channel blocking ayents as triest aro first line therapy used in adults in Australia.

The literature pertaining to pre-treatment with calcium prior to using these egents in the treatment of S.V.T. is reviewed and the practical aspects of calcium pre-treatment are outlined. A review of recent research pertaining to calcium channel blocking agents. ddenosine and other drugs relevant to S.V.T. is presented.

Evaluation of New Rapid Quantitative Immunoassay for Myoglobin versus CK-MB for Early Diagnosis of Myocardial Infarction

Charles McCuskey, MD, Gerard X. Brogan, MD, FACEP, Solomon Friedman, PhD, Jay Bock, MD, PhD, David Cooling, MD, Luis Berrutti, MD, and Henry Thode, PhD. Departments of Emergency Medicine and Pathology, State University of New York, Stony Brook, NY, 11794

Early identification of AMI in ED patients is critical for early triage and management. This study evaluated a new rapid serum myoglobin (S-Mgb) quantitative assay (Baxter, Stratus) vs. CK-MB (Baxter, Stratus) for ruling out AMI shortly after presentation. This prospective, observational study enrolled 189 patients over 30 years of age with duration of symptoms (chest discomfort, dyspnea, syncope, congestive heart failure, dysrhythmia, pulmonary edema, epigastric pain) less than 12 hours. Trauma pr renal failure patients were excluded. Serial testing was done at time of presentation (time 0 ) and 1 hour later (time 1). Normal S-Mgb values were defined as less than or equal to $110 \mathrm{ng} / \mathrm{ml}$. Using WHO criteria, 29 AMI patients were identified. Respective sensitivities of S-Mgb vs. CKMB were $55 \%$ vs. $23 \%(p<.05)$ at time $0 ; 73 \%$ vs. $41 \%(p<.05)$ at time 1 . Respective specificities of S-Mgb vs. CK-MB were $98 \%$ vs. $100 \%$ at time $0 ; 96 \%$ vs. $100 \%$ at time 1 . Negative predictive values, respectively, of S-Mgb vs. CK-MB were $94 \%$ vs. $91 \%$ at time $0 ; 96 \%$ vs. $93 \%$ at time 1 . In patients presenting within 3 hours of symptom onset, the respective sensitivity, specificity and negative predictive value of $\mathrm{S}-\mathrm{Mgb}$ vs. CK-MB were; $58.82 \%$ vs. $23.53 \%$ ( $p<.05$ ), $95.58 \%$ vs. $100 \%$, and $96.11 \%$ vs. $93.30 \%$. This rapid quantitative assay for S-Mgb was statistically more sensitive than CK-MB and had a better negative predictive value than CK-MB in the diagnosis of AMI in patients presenting within 3 hours of symptom onset.
The Dangerous Spiders of Sydney

Atrax robustus and Hadmonyche sp. (the Funnel-webs), Missulena sp. (the mouse spiders)

These spiders unique to eastern Australia are among the most venomous land animals in the world. The biology and the venom of these spiders is discussed. Some case histories are presented and medical treatment reviewed. 


\section{Track A}

A12

Study objective: To compare the effectiveness of IV and PR prochlorperazine in the treatment of benign vascular or tension headache.

Design: Prospective, randomized, double-blind trial.

Setting: Rural university emergency department with annual census of 50,000 .

Participants: Forty-five adult patients enrolled on 46 visits.

Interventions: Patients were randomly assigned to receive $10 \mathrm{mg}$ prochlorperazine IV and placebo suppository (IV Group), or $25 \mathrm{mg}$ prochlorperazine per rectum and placebo intravenous injection (PR Group). A $10 \mathrm{~cm}$ visual-analog scale (VAS) was used to assess pain at initial presentation and at 30 and 60 minutes after drug administration.

Results: At 60 minutes, IV Group patients had a mean VAS of 0.6; PR Group patients had a mean VAS of $3.5(p=0.0001)$. Two IV Group patients $(8.7 \%)$ and six PR Group patients (26.1\%) required additional analgesia prior to discharge $(p=0.04)$. No patient achieving pain relief with prochlorperazine by either route had headache relapse requiring repeat physician visit within 24 hours.

Conclusion: Intravenous is preferable to rectal prochlorperazine for relief of benign headache. Both routes of prochlorperazine compare favorably with other headache medications with respect to pain score reduction, rescue medication requirement, and headache relapse.

\section{Validation of Diphenhydramine as a Dermal Local Anesthetic}

Study objective: Diphenhydramine has been recommended as an alternate local anesthetic for patients claiming an allergy to lidocaine. No controlled evaluations of diphenhydramine for dermal anesthesia have been performed, although case reports cite efficacy. We wished to determine the relative safety and efficacy of diphenhydramine when compared to lidocaine and saline placebo.

Design: Prospective randomized double-blind clinical trial

Setting and patients: 24 healthy adult volunteers

Interventions: Subjects received intradermal $0.5 \mathrm{ml}$ injections of diphenhydramine $1 \%$, diphenhydramine $2 \%$, lidocaine $1 \%$, and normal saline placebo in a randomized double-blind fashion. Pain of infiltration and the extent of anesthesia were measured over time.

Measurements and main results: Infiltration of both concentrations of diphenhydramine was significantly more painful than either lidocaine or saline. Diphenhydramine $1 \%$ produced anesthesia equivalent to lidocaine $1 \%$ with similar onset and duration. Diphenhydramine $2 \%$ was less effective than diphenhydramine $1 \%$, although this difference was not statistically significant. No complications of clinical significance were noted.

Conclusion: Diphenhydramine $1 \%$ is as effective as lidocaine $1 \%$ for dermal local anesthesia, although it is more painful upon injection. This drug appears to be a safe and effective alternative to lidocaine for local anesthesia in areas of excellent tissue perfusion, although the safety of diphenhydramine for poorly perfused areas (e.g., digits, pinna, nose) remains to be established.
A14

Introduction

Subcutaneous orbital emphysema is considered a well-documented but uncommon event following trauma. Sequelae are generally considered benign and self-limited, but serious local and systemic complications can result.

Methods

A retrospective audit of all medical charts with the diagnosis of orbital blow-out fracture (ICD 802.6, 802.7, 802.8) and/or orbital exphysema (ICD 376.89) was performed for the period 1/1/88 through 12/31/92. The following data points were assessed: age and gender of patient, presence of orbital emphysema, mechanism of injury, diagnosis, $x$ ray/CT results, management, length of hospital stay, discharge where appropriate, and follow-up including complications.

Results

147 charts were reviewed. $16 \%(n=23)$ qualified based on the presence of orbital emphysema. The average age of the patient was 33 years (range 9-97), and the male $(n=20)$ to female $(n=3)$ ratio was 7:1. A traumatic pathogenesis occurred in all cases. $74 \%(n=17)$ of patients required hospitalization with an average duration of 10 days (range $0-29$ ). The pattern of fracture injury was as follows: $O . S .=7, O . D .=2$, O.U. $=2$, none $=2.83 \%(n=19)$ were managed with antibiotics. $46 \%(n=10)$ of patients had significant complications. Only one patient was lost to follow-up.

Conclusions

Orbital emphysema is not uncommon with facial trauma and is often associated with prolonged hospitalization and significant complications. The condition may occur without fracture. While prophylactic antibiotics are traditionally given, they may not be necessary.

\section{A 15 Pharmacokinetics of Prilocaine in Intravenous Regional Anaesthesia}

J. Hendrie, L.Smyth, N. Berlinski, C. O'Callaghan, W. Louis

Austin Hospital, Heidelberg 3084, Victoria, Australia

AIM

This prospective trial set out to determine the acute pharmacokinetics of Prilocaine used for intravenous regional anaesthesia (IVRA) procedures.

METHODS

14 patients, undergoing IVRA for forearm fractures, had Prilocaine levels taken both before and after tourniquet release. A dose of $2.5 \mathrm{mg} / \mathrm{kg}$ was used in all patients; a minimum occlusion time of 20 minutes elapsed in all instances.

RESULTS

No patients had detectable drug levels prior to tourniquet release. Peak drug concentration were reached within 10 minutes of tourniquet deflation. By 30 minutes, relatively minima drug concentrations $(<0.69 \mathrm{mcg} / \mathrm{ml})$ were reached in all patients. The procedure was well tolerated in children in whom no toxic levels were noted.

\section{CONCLUSION}

These results confirm that Prilocaine used at a dosage of $2.5 \mathrm{mcg} / \mathrm{kg}$ is safe. They also suggest that an observation period of $30 \mathrm{~min}$ following IVRA is sufficient and practical provided sedation and narcotics are not administered. 


\section{Track B} B11 THE EPIDEMIOLOGY OF EMERGENCY CARE IN A DEVELOPING COUNTRY: THE

Objective: To describe the epidemiology of ED cases in relation to the practice of emergency

medicine in a developing country.

Setting/Design: Trinidad is an island-nation of 1,864 sq. mi., a pop. of 1.25 million, a per capita GNP of $\$ 4,120$ ( $\$ 18,570$ USA). Two 14 day prospective surveys were conducted at the ED of the national referral hospital (1015 beds) with 100,000 visits/yr. The first was of all ED visits (3710), the second of injuries only (774 visits). The ED is directed by a surgeon, care is provided by 21 physicians, none with EM training, only one residency-trained (FP).

Results: Patient age and sex, types of cases and the time and day of arrival were similar to the USA. The most common overall diagnosis ( $40 \%$ of total) were injuries ( $38 \%$ lacerations, $34 \%$ STIs, $20 \%$ fractures, $14 \%$ sprains). $20 \%$ resulted from intentional violence. Respiratory diseases, especially asthma, were the most common medical diagnosis ( $13 \%$ of total). There were 10 deaths: 6 MIs and 4 MVAs. $40 \%$ of patients were admitted. The mean waiting time was 31 minutes and mean total ED time was 1.8 hours (max 5.75 hrs). $25 \%$ of patients received $x$-rays, 10\% IVs, $9 \%$ blood tests, $8 \%$ sutures and $<2 \%$ an ECC.

Conclusions: Case type and distribution was similar to USA inner-city EDs, but with more injuries and interpersonal violence, although fewer firearm injuries. ED physicians are not equipped to deal with the scope or complexity of their cases as evidenced by the $40 \%$ admission rate. Post-graduate EM training would improve ED care.
B12

A RANDOMIZED, DOUBLE-BLIND, COMPARATIVE STUDY OF THE EFFCACY OF KETOROLAC TROMETHAMINE VERSUS MEPERIDINE IN THE TREATMENT OF ACUTE RENAL COUC

Objective: To compare the efficacy of $I M$ ketorolac and meperidine in the treatment of acute renal colic.

Setting: Academic emergency department (ED/A\&E) with 76,000 annual visits.

Design: Prospective, controlled, randomized, double-blind trial.

Participants: Volunteer ED patients with an IVP-confirmed diagnosis of renal colic. Interventions: Subjects were randomized 1:1 to receive a single $\mathrm{IM}$ injection of either $60 \mathrm{mg}$ ketorolac or 100-150 mg meperidine, based on weight. Results:

Of 70 patients completing the trial, 33 received ketorolac and 37 received meperidine. Demographic characteristics and baseline pain scores of both groups were comparable ( $P=N S$; Mann-Whitney $U$ ). Ketorolac was significantly $(P<.05)$ more effective than meperidine in reducing renal colic at 40,60, \& 90 minutes as measured on a $10 \mathrm{~cm}$ visual analogue scale. Most, (64\%) ketorolac-treated patients reported "a lot" or . "complete" pain relief after $\mathbf{4 0}$ minutes compared to $39 \%$ of those treated with meperidine $(\mathrm{P}<.05)$. Similar proportions of patients in each group were given rescue analgesia and admitted. Of patients who were discharged home without rescue, those treated with ketorolac left the ED significantly earlier than those treated with meperidine ( 3.46 vs 4.33 hrs, $P<0.05$ ).

Conclusion: $\mathrm{IM}$ ketorolac as a single agent for renal colic is at least as effective as meperidine and promotes earlier discharge of renal colic patients from the ED. 


\section{Track C}

The Prevalence of Unrecognized Prognancy in an Urban Baergency Department

Objective: Women presenting to the Emergency Department often undergo $x$ ray examinations or are prescribed medications which could be harmful to an unauspected pregnancy. Thls 1s the first atudy to look at the prevalence of pregnancy in all women presenting to an Bmergency Department. Historical risk factors were analyzed to define which women need a pregnancy test in the ED. Design: Prospective study.

Setting: Urban community ED with annual census of 38,000 .

Participants: 191 consecutive women who presented to the $\mathrm{ED}$, met inclusion criteria, and consented to the study. Inclusion criteria were menstrual period within the last 10 months, not known to be pregnant, and no hyaterectomy. Urine pregnancy teste were performed on all those enrolled. A menstrual and sexual hletory questionnaire was also completed. Physicians were blinded to the study, and their pregnancy test ordering was recorded.

Results: 12/191 (6.3i) were pregnant. Wowen with abdominal/pelvic complaints had a 13t prevalence (9/69) whereas other complalnts had a 2.5 s prevalence (3/122). Historical risk factors were analyzed using the Flaher's exact test with $p<0.05$ considered significant.

\begin{tabular}{|c|c|c|}
\hline 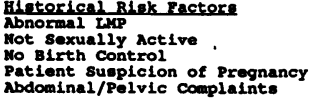 & $\begin{array}{l}\frac{p-\text { value }}{0.0067} \\
0.437 \\
0.133 \\
0.0002 \\
0.0011\end{array}$ & $\begin{array}{c}\text { Relative } 3 \text { isk } \\
50.77 \\
0.84 \\
22.93 \\
22.71 \\
6.43\end{array}$ \\
\hline
\end{tabular}
Physicians ordered 73 pregnancy tests and missed 2 pregnancies (sensitivity 838, specificity 65t). If pregnancy tests had been ordered on women with historical risk factors of abdominal/pelvic complaints, abnormal LAP, or patient's suspicion of pregnancy, 94 teste would have been ordered and $O$ pregnancies missed (sonsitivity 1008, specifleity 54i).

Conclusion: Historical risk factors identified all women with unrecognized pregnancy. All women with abdominal/pelvic complaints should have a pregnancy test. In women without abdominal/pelvic complaints, a pregnancy test is needed only in those with an abnormal LMP or patient's suspicion of pregnancy.

$$
\text { MR. M. GAVALAS FRCS }
$$

ACCIDENT \& EMERGENCY DEPARTMENT, WHIPPS CROSS HOSPITAL, LONDON, E11 INR

Objective: To establish whether SHOs in A\&E (i) understand Anaphylaxis and its management; (ii) have received any form of teaching on Anaphylaxis during their six months in post and if there are departmental guidelines/protocols on its management.

Design: 60 A\&E SHOs (from A\&E Departments in the North Western and North East Thames Regions) selected at random in the sixth month of their appointment, were interviewed in private without prior warning following a set pro-forma.

Results

- $38 / 60$ of the SHOs (63X) did not consider Anaphylaxis as an unpredictably progressive condition which can become life-threatening very rapidly. Defining severe/1ife-threatening Anaphylaxis, hypotension/impaired perfusion and gastrointestinal signs were not considered by $22 / 60$ (37x) and $45 / 60$ (75x) respectively; equally worrying, only 21/60 (35x) named Adrenaline as the essential drug for $i$ ts treatment and 49/60 (81X) did not know the dose. 52/60 (86x) could not calculate the concentration of the drug in $\mathrm{mg} / \mathrm{ml}$ from ampules marked $1: 1000$ and $1: 10000$

$32 / 60(51 x)$ did not include supplemental oxygen administration and 44/60 (75x) did not understand the meaning and significance of $\mathrm{FIO}_{2}$ and how to provide maximal oxygen concentration therapy. Of the $38 / 60$ (63\%) including IV fluids in their management, $40 \%$ did not know what volume to administer.

- None of the SHOs received any training/teaching in Anaphylaxis whilst in post in A\&E and none of the A\&E Departments had protocols on its management.

Conclusion: There is a widespread ignorance amongst A\&E SHOS in the management of severe/life-threatening Anaphylaxis, which is paralleled by a total lack of training and clinical protocols in A\&E Departments. Our Anaphylaxis Protocols show that the treatment of Anaphylaxis depends on its clinical stage of severity (Rings I-JV).

Anaphylaxis, SHO Training, Adrenaline

\section{C9 A NATIONAL SURVEY OF GMTRGENCY NURSE PRACTITIONERS}

(Nurse Practitioners in Accident \& Emergency) objective: To establish the prevalence of "Emergency Nurse Practitioners" (ENPS) in Accident \& Emergency Departments in England and wales, and identify variations in working practices.

Design: A postal survey of all 465 functioning Accident \& Emergency departments in England and wales in January 1994, following a pilot study in Southwest Region.

Results: 313 replies have been received from 465 sent (67\%) so far. A final rate of $80 \%$ is expected.

Overall, 141/313 (45\%) of departments use E.N.P.'s, and in major departments $49 / 173$ (28\%). However, $85 \%$ of this group started in the last 5 years, and a further 63 plan to start by the end of 1996; this will represent 648 of major departments.

In $70 z$ of major departments using them, E.N.P.s see less than $10 \%$ of new patients. Conversely, in only 8.28 of minor departments do the E.N.P.S see less than 108

In major departiments using E.N.P.'s, 758 allow prescribing by E.N.P.'S, and in 528 can request $X$ Rays.

668 blamed radiographers for restricting the role of the nurse practitioner.

10/49 (208) of major departments used E.N.P's without formal training.

Conclusions: Nurse practitioners in major Accident \& Emergency Departments are a recent and rapidly growing phenomenon, yet there is wide variation in training and permitted activity.

Nurse practitioners in major departments see a much smaller percentage of patients than in minor departments, probably due to different working practices.

Despite controversy over the legal position, prescribing by E.N.P.'s occurs in $75 \%$ of major departments. Radiographers are perceived by $66 \%$ of major departments as the main group restricting the role of their E.N.P. STEVE MEEK \& GOLDIE RUFFLES, Accident \& Emergency Department, Frenchay Hospital, Bristol. 


\section{Track D}

D11 Title: Pediatric Head Trauma: enhanced prediction of positive computed tomography by pediatric trauma score and Glasgow coma scale

Objective: To determine if either the initial Glasgow Coma Scale (GCS) or Pediatric Trauma Score (PTS) can predict intracranial pathology as evidenced by abñormal CT scans (HCT) in pediatric head injuries. Design: Prospective observational study from 1/1/92 - 12/1/92. Setting: 450 bed tertiary care university hospital with an ED volume of 100,000. Participants: 94 children (ages 2-15) underwent HCT and were admitted to the pediatric trauma service. Data included age, GCS, PTS, HCT results, and Delta score. Results: Of 94 patients, 65 (69\%) had a normal HCT and 29 (31\%) had abnormal HCT. Patients with abnormal HCT had PTS $12(n=1)$, PTS 9-11 $(n=6)$, and PTS $<9(n=23)$. The GCS in the abnormal HCT group included GCS $15(n=7)$, GCS 10-14 $(n=8)$, and GCS $<10(n=14)$. The 7 patients with abnormal HCT and normal GCS required no intervention and suffered no neurologic sequelae (Delta score). Listed below are the sensitivities and specificities of abnormal GCS and PTS scores (both individual and combined) at selected cutoffs. The confidence interval for all scores was $95 \%$ :

$\begin{array}{lllll} & \text { GCS }<15 & \text { PTS }<12 & \text { PTS }<9 & \text { GCS }<15 \text { or PTS }<9 \\ \text { sens } & .76(.56-.90) & .97(.83-1.0) & .77(.58-.90) & .83(.64-.94) \\ \text { spec } & .78(.67-88) & .03(.00-11) & .60(.47-.72) & .54(.41-.66)\end{array}$

Conclusion: Our study suggests that in pediatric head trauma, a normal GCS does not preclude abnormal HCT. Utilizing PTS $<12$ results in a highly sensitive predictor of abnormal HCT, but lacks specificity. A combined PTS $<9$ and GCS $<15$ increased sensitivity, but decreased specificity. The PTS appears to be a good measure of the magnitude of trauma. A normal GCS and normal PTS are predictive of a normal HCT.

IITLE: The relationship between the Glasgow coma score and the cough reflex AUTHORS: Christopher Moulton and Alan Pennycook

ADDRESS: Manchester Royal Infirmary, Manchester M13 9WL ABSTRACT:

Objectives: To discover what relationship, if any, exists between the level of consciousness [as defined by the Glasgow coma score] and the state of the cough reflex

Design: Observational recordings by 2 doctors participating in the patients' treatment no change to any routine practice

Subjects: 76 patients presenting to $A \& E$ in coma of any cause [GCS $=$ or $<8$ ]

Setting: Departments of Accident and Emergency Medicine

Main outcome measures: The state of the cough reflex [graded as normal, attenuated or absent]. The GCS and the cause of the coma were also noted.

Results: The state of the cough reflex was found to bear no fixed relationship to conscious level as defined by GCS in comatose patients presenting to $A \& E$.

Conclusions: All comatose patients presenting to A \& E must be treated as if their airway is at risk. However, even at the lowest levels of the Glasgow coma scale there are many patients whose ainway reflexes are sufficiently intact to make procedures such as endotracheal intubation difficult or dangerous without the use of drugs. The state of the airway should thus be assessed independently of conscious level.

Additional notes: This work is the follow-up to the paper discussing the relationship between the Glasgow coma score and the gag reflex which I presented at the B.A.E.M ' 91 conference in Scarborough. It has not yet been published although it has been provisionally accepted by the Lancet [subject to alterations]

Kenwords: COUGH REFLEX, GLASGOW COMA SCORE

\section{CLOSING THE AUDIT LOOP WITH A HEAD INIURY}

Head injuries are an important cause of morbidity, mortality and long term disability, often in otherwise healthy young people. It has been estimated that in an average district over a period of a year, $11 \%$ of all patients attending A\&E have suffered a head injury $(5,000-7,000$ patients), ${ }^{1}$ one third to one half of these are under 14 years of age, ${ }^{2} 750$ are admitted, ${ }^{3} 25$ die and 25 are left with sufficient disability to need care and support from hospital and community services. ${ }^{\star}$

It is the management of these injuries in the Accident and Emergency (A\&E) department that plays a key role in the diagnosis and treatment of potentially avoidable secondary brain damage.

In South East Thames Region, much work has been undertaken to improve the quality of documentation and acute management of head injuries in the accident and emergency department. Data will be presented from studies that have examined the notes of almost 3,000 patients with a head injury.

A retrospective criterion based audit was undertaken to assess if the management of head injuries in two A\&E departments in Brighton satisfied recognised guidelines for ordering a skull X-ray (SXR) and computerised tomogram (CT scan), and admitting a patient with a head injury."

Results from the audit suggested that of the 158 notes reviewed, $132(84 \%)$ patients satisfied the management criteria while $19(12 \%)$ failed the SXR, $4(2 \%)$ failed the admission and 3 (2\%) failed to satisfy the CT criteria.

An important conclusion from the audit was that the information in the medical records was of poor quality, both in content and legibility. This made it more difficult to objectively decide whether a patient had been appropriately managed according to the criteria, suggesting that the result of $84 \%$ correctly managed patients may be too optimistic, and the true figure much less. 


\section{Wednesday 25 May 1994}

\section{Plenary Session}

COMPARISON OF HIGH-DOSE EPINEPHRINE VS STANDARD-DOSE EPINEPHRINE IN ADULT CARDIAC ARREST IN THE PRE-HOSPITAL SETTING ABSTRACT

OBJECTIVE: To compare the efficacy of high-dose epinephrine (HDE) with standard-dose epinephrine (SDE) in the management of cardiac arrest in adults in the pre-hospital setting DESIGN: A twelve month retrospective study of SDE and a twelve month prospective trial of HDE.

SETTING: Pre hospital setting in a mixed geographical area over 2200 square miles with a population of 700,000 .

PARTICIPANTS: Adult patients in cardiac arrest.

INTERVENTIONS: Paramedics treated out of hospital cardiac arrest patients. In the control group, patients were treated according to existing American Heart Association cardiac resuscitation guidelines using SDE (defined as 1.0 milligram boluses to a maximum of 4 milligrams). In the test group, the same guidelines were revised to employ HDE (defined as a rapid sequence of 5,10 , and 15 milligram boluses to a total of 30 milligrams). RESULTS: The control group included 594 patients, the test group 580. Overall survival to hospital admission in the control group was 84 patients (14.5\%) and in the test group 89 patients (15.3\%). Survival to hospital discharge in the control group was 29 patients (4.88\%) versus 28 patients (4.83\%) in the test group. For patients whose initial rhythm was ventricular fibrillation, survival to admission in the control group was 39 patients (20.4\%) versus 43 patients $(24.4 \%)$ in the test group. Survival to discharge for patients presenting with ventricular fibrillation in the control group was 17 patients (8.9\%) versus 19 patients (10.8\%) in the test group. CONCLUSION: There was no statistically significant difference in overall rate of survival to hospital admission or discharge between patients treated with SDE and those treated with HDE, regardless of the presenting rhythm.

Study Objectives: To evaluate the use of $\mathrm{ETCO}_{2}$, as a predictor of resuscitation, in prehospital cardiac arrest patients, with pulseless electrical activity (PEA) .

Design: A prospective study of 90, consecutive, prehospital, cardiac arrest patients with PEA comprised the study group. All were intubated and evaluated by mainstream ETCO, monitoring (Cosmos, Novametrix Inc., Wallingford, CT.) both to confirm ET tube placement and assess resuscitation. All were treated by our standard ACLS protocol, under online medical control. The decision to continue, transport, or cease resuscitation was based primarily on $\mathrm{ETCO}_{2}$ levels. Data was analyzed using a t-test (alpha $=0.05$ ).

Results: There were 61 male and 29 female patients (mean age 68.5 years, range 27-95 years). Initial $\mathrm{ETCO}_{2}$ averaged $11 \mathrm{~mm} \mathrm{Hg}$ in survivprs (Range 5-24) and $11.9 \mathrm{~mm} \mathrm{Hg}$ in non survivors (Range $5-50$ ) $\mathrm{P}=\mathrm{NS}$. $\mathrm{ETCO}_{2}$ prior to ceasing resuscitation, in the field, averaged $4.4 \mathrm{~mm} \mathrm{Hg}$ (Range 0-12). In survivors, just prior to clinical restoration of circulation (ROSC), it averaged $28.6 \mathrm{~mm} \mathrm{Hg}$ (Range 1635) $P<0.05$. There were 15 survivors (9 died in hospital, 6 discharged) and 75 non survivors. The decision to stop resuscitation in the field in the presence of PEA was made, under online medical control, solely on the basis of the $\mathrm{ETCO}_{2}$ remaining at or falling from a level of $12 \mathrm{~mm} \mathrm{Hg}$. In 11 of 12 survivors the first evidence of ROSC was a rising $\mathrm{ETCO}_{2}$.

Conclusion: This study suggests that the measurement of $\mathrm{ETCO}_{2}$ may provide a useful adjunct in gauging the likelihood of field resuscitation in patients with PEA. Additionally, it may be an early indicator of ROSC. Lastly, by delineating patients who cannot be resuscitated, it may prevent unnecessary emergency transports, with potential risk to prehospital providers and others.

\section{7 Out of Hospital Cardiac Arrest - How many lives can be saved? Peter Cameron}

AIM

Sudden cardiac deaths occurring within 24 hours of the first symptoms account for nearly one third of all people dying from coronary artery disease in the U.S.A. (annual incidence 124 $/ 100,000$ population)

Experience from some centres would suggest that up to $30 \%$ of the deaths may be preventable if optimal pre-hospital care systems are in place. These reports do not take account of the large difference in reported annual incidence of cardiac arrest / 100,000 population (35-130). Despite allowance for differing population samples, there are still significant differences in Despite allowance for differing population samples, there are still significant differences in
outcome between communities. The major interventions which have been demonstrated to be useful and cost effective, are early defibrillation and bystander C.P.R. Both these interventions require community participation and education rather than medical expertise. The addition of advanced airway techniques and pharmacotherapy have not been conclusively demonstrated to improve survival in the out-of-hospital environment. Immediate access to the Emergency Medical System (EMS) is crucial and EMS co-ordinators must maintain a flexible approach depending on geography and resources.

The introduction of the Utstein criteria for reporting of results will help clarify some areas of ambiguity in the management of out-of-hospital cardiac arrest.

Most communities can improve their survival rates from cardiac arrest, but need to develop a community strategy for C. P. R. training and early access to defibrillation. 


\section{Track A}

A16 The Public Health Implications of Air Bag Restraint Systems in The United States

Study objective: Motor vehicle crashes are the leading cause of injury deaths in the United States. The purpose of this study was to determine the safety and efficacy of air bag passive restraint systems currently in use in the United States.

pesign: Retrospective review of data collected by independent sources from 1984-1993 in the United States. Sources included the Fatal Accident Reporting System (FARS), the Highway Loss Data Institute (HLDI) and the National Highway Traffic Safety Administration (NHTSA).

Btudy population: Occupants of air bag equipped vehicles who were involved in crashes on United States roads.

Results: Relative to comparable cars with manual seat belts only, driver fatalities in air bag equipped cars were reduced by 298 in frontal crashes and by $20 z$ in all crashes. Drivers also had a $25 \%$ decrease in moderate to severe injuries and were 248 less likely to require hospitalization. Air bag deployments have reduced head and torso injuries. Finally, of 572 occupant injuries related to air bag deployment, all were classified as minor (98.3z) or moderate (1.78); most were abrasions and contusions.

conclusions: Air bags represent a safe and effective technology, alter both extent and type of injuries observed and significantly reduce crash fatalities.

In the southeastern United States, the building code standard for guardrail spacing is 6 inches. The majority of children under seven years old can pass through a 6 -inch, but not a 4-inch, wide opening. Thus, the balconies, stairways, decks and porches with 6 inch guardrail spacing are ineffective barriers for small children.

A search for children hospitalized in our large urban children's hospital with E-Codes for falls (E880-808, excluding 886) from 1990-1992 was conducted. Charts were reviewed for demographic information, details of the fall, medical status of child on arrival, hospital course, and total charges.

A series of five cases was found. Children ranged from 15 months to 4 years. Four were males. Two falls occurred in private residences, two in public housing, and one at a school. Injuries included skull fractures and long bone fractures, with a fatal injury in the 4 year old. Hospital charges alone total over $\$ 69,800$ for these 5 cases.

The current standard of a six inch spacing on guardrails creates an unnecessarily hazardous environment for our community's preschoolers.
A19 Do seat belts in buses save lives? - A review of injuries sustained by unrestrained casualties involved in a fatal bus crash in relation to their seating positions

M. J. Williams, FRCS(Glasg.) FFAEM, A. R. Wass, FRCS

Accident \& Emergency Department, York District Hospital, Wigginton Road, York, North Yorkshire YO3 $7 \mathrm{HE}$

In September 1993 on the A1079 York to Hull road there was a fatal road traffic accident involving a double decker bus full of school children and an articulated lorry. The paper analyses the injuries sustained by the casualties from this accident in relation to their position in the vehicle at the time of the accident.

The bus sustained severe structural damage. Although none of the children were restrained, there were no serious visceral or chest injuries. This paper reviews the current research into the use of restrains in buses and relates these findings to the above accident. It also considers the problems of safety in relation to the exits from the vehicle and the need for reviewing the designs of escape exits on older vehicles.

BUS DESIGN, INJURIES, RESTRAINTS 


\section{Track B}

\section{B16}

Immedlate Care under Resource Constraint (ICUR): A Modular Training

V Gautam, C J Holliman.

Emergency Medicine Department, Hershey, Pennsylvania.
York House, Queen Alexandra Hospital, Coshan. Portsmouth.

A skill based modular training programme for Emergency Medicine is presented in this paper. It has developed from the authors' experience of training colleagues in countries where emergency care 18 provided under serious resource present.

The programme defines standards and provides a flexible but practical approach to training for emergency medicine. It adopts the well proven non-traditiona methods of ATLS/ACLS courses and extends these principles to range of

A background to the programme and the essential detalls of it together with preliminary data about 1ts effectiveness will be discussed in the paper.

Modular Training, Resource Constraint, Standards, Practical Approach, NonTraditional Victims of urban volence managed in an Emergency Department in Paris,
France. Results of a 6-month, prospective study.

study purpose. To identify the incidence, morbidity and sociodemographic features of Victims of Urban Violence (VUV) in the Emergency Department (ED) of a 700-bed, University Hospital, in Paris.

Design. All consecutive protagonists of UV were included. Collected data were : characteristics of victims and aggressors, day, time, place and means of viperitcome of UV

Results. From E.D. patients $(n=16157$ ), were treated. Monthly incidence was unchanged. E.D. patients $(n=16157)$. were treated. Monthly incidence was unchanged Thurs. (5.2 $\pm 2.5 \%$ to $5.6 \pm 2.4 \%$; NS), it increased to $7.1 \pm 3.3 \% \mathrm{Fri}$. and Sat (p<0.03) and peaked to $9.3 \pm 3.0 \%$ on Sun. (p<10-6). Furthermore during the 6 holidays of the study, incidence of UV was significantly higher $9.4 \%$, range $2.1-14.1 \%)$. than that of any other weekday $\left(\mathrm{p}<10^{-6}\right)$ except Sun. For a given day. UV occurred mostly between 8 p.m. and 4 a.m. (40\%). Means of UV were firearms in $1.1 \%$ of cases, blades in $23 \%$, blunt instruments in $24 \%$, and body means in $51.6 \%\left(p<10^{-5}\right)$. The sketched portrait of VUV is that of a male $(64 \%)$, aged $20-40$ years $(70 \%)$, with a job $(53 \%)$ and a home $(66 \%)$, attacked in a public place $(63.5 \%)$. by a person unknown to him $(54 \%)$. Outcome of UV was a superficial wound in $82.5 \%$ of cases, bone fractures in $12 \%$. viscera lesions in $3.6 \%$. Four patients died, $14(1.3 \%)$ were operated on, $42(4 \%)$ were hospitalized for observation and 11 left the ED before medical decision.

Conclusions. 1) Incidence of UV in our ED $(6.5 \%)$ is among the highest in France. 2) Its morbidity and mortality are not insignificant. Its long-term psychological impact is unknown. 3) Legally, medically and psychologically. ED physicians are poorly prepared to confront UV consequences.
THE SHANKILL ROAD BOMBING: EXPERIENCE OF THE AEE SERVICES

$$
\text { J O DORMAN, S O'REILLY, A MCMURRAY }
$$

MATER HOSPITAL AEB DEPT, CRUTLIN ROAD, BELFAST

Shortly after 1 pa on Saturday 23.10.93, a boab exploded in a crowded Fishmongers shop on Belfast's busy Shankill Road. Ten people vere killed and over 50 vere injured. The Bergency Response involved seven front-line anbulances, a hospital nedical tean and two A\&B Departments. All the fatally injured had been inside the shop, two of then died a short time after arrival at hospital, another man died during extrication. The remaining six bodies and the dismenbered remains of a further victin were found with the use of the Fire Service's thermal camera. The dead included two children - all had unsurvivable injuries. Nineteen patients vere transported to two neighbouring $\Delta \& B$ Departments, both of which had activated their Major Incident plans just under 10 minutes previously. Fifteen ambulance patients vere adnitted to the nearest A\&B at the Mater Hospital, the other three were taken to the Royal victoria Hospital. A further 37 "walking wounded" cane to the Mater Hospital which treated a total of 52 patients. In addition the Hospital was stormed by relatives desperate to find their fanilies and around 100 people responding to a bogus demand for blood donors. Issues raised at the Ambulance Service debriefing included the tenporary prevention of access to and from the scene by the arriving Energency Service Vehicles and also the deployment of the medical tean (who had not been wearing protective clothing and had been unable to enter the building). The $A \& B$ debriefing identified the desirability of having a Radiologist based at $A \& B$ X-ray as vell as the benefits of using separate floors of the Hospital to treat those with ainor injuries and to care for distressed relatives.

boab blast; anbulance service; najor incident plan. 


\section{Track C}

C11 TITLE: An Analysis of a United States Based Project to Strengthen Pre-Hospital Emergency Medical Services in Poland

PURPOSE: To analyze the structure and process variables of United States based training of Polish physician EMS groups including the influence of the sociological, political and cultural nexus among the US and Polish personnel, the dynamics of the three Polish physician groups, the social structure of the EMS Partnerships Project, and the attributes of their respective cultures and health care systems.

METHOD: A qualitative research method was used to analyze the EMS training in the United States including: direct observation of classroom activities, participants' final presentations, and US EMS group management meetings; analysis of project workplans, reports and communications; participant interviews.

RESULTS: The United States EMS group's knowledge of the Polish culture and Polish understanding of US EMS organization and practice were critical. The success of the EMS training was strongly related to each Polish groups' ability to coalesce and work collaboratively. Selection of Polish physician participants determined team formation and had significant implications for training effectiveness. The Polish physician groups' capability to overcome systemic barriers such as the absence of a developed primary care structure to manage the current $70 \%$ non-emergent calls was as salient as their clinical expertise in the effectiveness of the EMS training project.

CONCLUSION: Sociocultural variables are critical in the process and outcome of the training of Polish physician EMS groups. These variables contribute substantially to the effectiveness of the training project to achieve its ultimate outcome, the strengthening of the EMS system in Poland.

\section{Workshop A}

\author{
EMERGENCY MEDICTNE AND LATERAL THINKTNG
}

The systems development in health care that gave rise to the modern practice of Emergency Medicine is the consequence of changing the conccptions and perceptions associated with the initial reception and early management of acute clinical conditions.

The competent emergency physician, complete with appropriate clinical and investigative supports is the solution to the reformulation of the problem of how to best correct the deficiencies associated with a system where junior and inexperienced modical staff are actred to be responsible for managing serious and undifferentiated illness

In this sense Emergency Medicine can be understood to be the result of the application of lateral thinking to the seemingly intractable and recurrent clinical flaws in "Casualty".

The pext challenge is how to carry this momentum forward by the enlistment of a full and alert imagination and make the conceptual jumps that will realise the intelloclual potential of this unique postmodern discipline. Emergency Departments are situated at the interface of the society at large and the formal acute health care system. They are in truth a microcosm of civilisation. In them for example, can be seen some of the consequences of the intransigence of urban poverty, the decay of the public infrastructure, the growing brutality of interpersonal violence and a changing social order that is increasingly fluid and unfamiliar.

If this challenge can be met the potential exists to position emergency physicians into the thicket of every major contemporary social and intellectual debate.

There is no fundamental reason why emergency physicians, drawing on the material of their own practice cannot make major contributions to fields as diverse as domestic and criminal violence; systems evaluation; decision analysis and artificial imelligence; and even cultural and politica theory. Who, for instance, is better situated than the emergency physician to observe the consequences of the difficulties of reconciling diverse private intercsts with the public order? And, none of this precludes the potential to continue to exploit the vast range of opportunities to pursue orthodox clinical and basic medical approsch.

Emergency Medicine has already demonstrated that old paradigms can be made to yield to changes of real and lasting value. The opportunity exists for the third millennium to be witness changes of real and lasting value. The opportumity exists for the thind miliennium to be witness to a coalescence of creative intelligence that will recognise the Emergency Departunent as a key institution for intellectual productivity in our sociesies. This may seem an inflated, grandiose
claim but it is important to remember that it is difficult to conceptualise a decent civilised society claim but it is important to remember that it is difficult to conceptualise a decent civilised society
without a good system of emergency medical care. The challenge is there, "lateral thinking" can help make it a reality.

Joseph Epstein, FRACS, BA(Hons), FACEM Director of Emergency Medicine

Western Hospital

C13 Title: "Emergency Medical Services (EMS) in Riga, Latvia, a major city in the former U.s.s.R." Study objectives: To define, investigate and compare emergency medical services (EMS) provided in Riga, Latvia, a major city in the former U.S.S.R. with EMS provided in Philadephia, PA, U.S.A. Also, a survey served as a commentary and needs assessment of EMS in Latvia.

Type of participants: Fifty Latvian physicians (778), nurses (47), medical administrators (7t), medical educators (78), and other medical personnel (47) received the questionnaire.

Results: Forty (808) of the participants responded to the questionnaire. Strengths of current Latvian EMS include: physicians on most ambulance runs, existence of specialized ambulance brigades, and staff enthusiasm and spirit; weaknesses include: lack of medicine, modern equipment, supplies, education and training, and written standards, - and long ambulance response times. Data comparison Philadelphia (P) / Riga (R): population - 4,000,000/985,100; EMS calls/yr - 116,728/271,525; EMS patients transported to hospitals/clinics - 69,789/54,315

Conclusion: EMS in Riga, Latvia, is an integral part of the city's primary medical care system. Unlike in Philadelphia, Latvian physicians routinely staff ambulances and treat a wide range of medical problems in the home. "Paramedics" are used primarily for patient transport. 


\section{Thursday 26 May 1994}

\section{Plenary Session}

INCIDENT REPORIIMG IN THE ERERGENCY DEPARTMENT

J.Hondx10.J.smyth, D.stolla Emorgoney Dopartront, Austin Hospital, Holdolberg 3084

In

The purpose of this prospective study is to assose advarso incidents and identify proventable factors in thelx occurrence.

methons

An edvorse incident is definod as en event which affocts or could affect the enfoty of a patient.

The Incldents are reported by medicel staff on proformat sheots.

Attention 1s drawa to contributary and proventable factors(e.g. drug identification probleme and technical problems with equipment) The reports are anonymous, that is the namos of the reporter and the pationt aro not inciuded on the proformat sheot. The reports are reviowed at monthiy meotinga with a view to proventing a recurronce. Iesoris

The Ineldont report shoot constructed for the study w1ll bo outlined. To date, 60 edverge lacidents have beon reported in two months. 57 (95\%) of the incldents heve been classified as proventable. 94\% of the eorles were related to diagnostic orror. The principal corroctive otretegles proposed to dato inelude improved communication, additional tralniag, oquipment checking and ongolng quallty assurance activity. concusions

Roporting of adverse incidonts in a non punative syoten plays a potentialiy important role in thelr prevention it also provides an opportunity for staff training end oducation.initial results point to - greater yield than tradtional mobidity and mortality revieus in Emergeney modicline.
TITLE: Teaching Emergency Thoracotomy: Animal Model vs. Computer Simulation

Hypotheses: 1) Thoracotomy procedural skills can be assessed using computer simulation and pig modets. 2) Computer simulation practice improves procedural performance.

Design: Experimental, randomized, posttest-posttest, control group design.

Participants: Eighteen examinees, six each from three training levels (medical student, resident, faculty) at an Emergency Medicine Residency Program.

Interventions: All examinees memorized critical procedural content and watched procedure demonstrations on computer. Examineees were then randomized to either thoracotomy or cricothyrotomy (control) computer simulation practice. Procedural competency was assessed for three thoracotomy procedures (opening the chest, pericardiotomy, and aortic cross-clamping) using both computer and pig models.

Results: Three performance scales were developed (reliability): 1) Pig Time (.46), 2) Pig Accuracy (.59), and 3) Computer Accuracy (.71). Analysis of variance statistics were used to assess the effects of training and thoracotomy practice upon performance scores. The time to complete all three thoracotomy procedures (Pig Time) for medical students (15.1 $\pm 2.3 \mathrm{~min}$ ) was greater than residents $(8.6 \pm 2.2 \mathrm{~min})(p<.007)$. Faculty had fewer errors of commission or omission on the pig (Pig Accuracy) $(p<.020)$. Examinees with thoracotomy computer practice performed better on the computer model (Computer Accuracy) $(p<.020)$.

Conclusion: 1) The pig model discriminated among examinees known to differ in training more often than the computer model. 2) Computer simulation practice improves procedural performance on the computer by not the pig model. 


\section{Track A}

A20

\section{VIDEOTAPING OF TRALIMA RESLSCTTATIONS}

A method of critical incident monitoring

P GAUDRY

WESTMEAD HOSPITAL

Westread Hospimal opened in 1978. It is a teaching hospital of the University of Sydney and is stroand almost in the geographical centre of Sydney. It serves a referral arca and is siroand almost in the peographical centre of Sydrey. If serves a referral arca population of 1.5 million and district area population of 310,000 . It has maintainod a

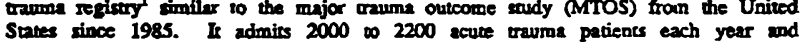

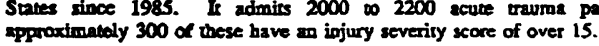

White unuma resusciations have a low froquency relative to the cotal number of patients presoning 10 the emergency deparment, they are characterised by a bigh level of concenuration and high expectasions of peformance. However the argency of the resusciution limis the rzama team from having the opportunity to reviow perfarmance and to relate that performanoe to outcome. Hoyt et al have reported their experience using videoraning of trumen resoscisations, combined with detriefing of the individuals invalved in a perticular resuscivation and specific fookage was vitilised at resuscitarion

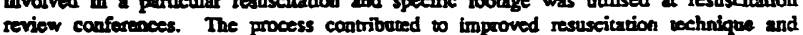
reviow coaforemoes. The process contributed to improved resuscication uochnique and emessency doparment at Westomead Hospinal in 1993.

The initial experience suggens that it is effective in real ime improventent in trauma resuscitation. The tochnique also has porential for use in critical incident moniboring. However there is a rectuetance of cliniciens to seek individual instructional foedback and experience using the upes wo facilitzte tranme debrief meecings is limited.

References

1. Deane SA, Read C, Gaudry P, Robers R.

Esrablishment of a trauma registry. Aust NZJ Surgery 1988 58: 245.

2. Hoyt DB, Shuckford SR, Fridland PH, Mackersie RC, Hansbrough IF, Wachtel $\mathrm{TL}$, Fortune $\mathrm{JB}$.

Videorecording trama resuscitations: an effective reaching rechnique.

3 Trauma $198828435-440$.
The Trauma Forum: How to win friends and influence poople.

Luke L C Shepard G J.\& Mukherji M.

A\&E Department, Royal Liverpool University Hospital, Prescot Street, LIvEnpool L7 $8 \times 0$

The impact of trauma on society has been well described in the past cecade and a number of national initiatives have been established with the aim of improving trauma care in the U.K. eg the A.T.L.S. courses, the Major Trauma Outcome Study and the U.K. Trauma centre pilot study based at Stoke. Fewer local initiatives have been publicised al though local factors can produce unusually effective responses to the injured patient. A local endeavour in the Royal Liverpool University Hospital has been the Trauma Forum (TF), amonthly interdisciplinary meeting, in which the trauma case load for each month in the RLUH is described in detail, educationa aspects are illustrated and constructive criticismof the hospitals response to trauma propounded. The establishment of the $T F$ has seen a greatly enhanced interdisciplinary cooperation in trauma care with formal Injury Severity Scoring, a substantially improved early imaging service, better documentation and greatly clarifed overview of the impact of injury on the hospital. The TF meeting has grown steadily in popularity across not only the hospital but across the region and there has been a constant demand from

colleagues at every level for invitations to attend. In this paper the way in which the TF has developed is described together with an analysis of the patient load. institutional response and the growing attendances at the meetings. The benefits of such a meeting along with the difficulties, pitfalls and limitations of organisation are outlined and a similar multidisciplinary platrorm for the analysis and development of an institution's response to trauma is commended to all colleagues in Accident \& Emergency Medicine throughout the UK.

Trauma, Interdisciplinary meeting, Organisation A23 TITLE : What risks are associated with unscheduled returns, and how can those risks be AUTHOR(S): Ms. Ruth Brown, FRCS, Senior Registrar in Accident \& Emergency Medicine

Address Department of Accident \& EmergencyMedicine, St. Georges Hospital, Tooting, London SW17 0QT

Objective. Reports of the numbers of unscheduled returns to the Accident and Emergency Department range from $0.4-2.2 \%$ of all attendance's. These reports make it clear that many of the unscheduled visits are avoidable amd represent failures in Doctor -patient communication as well as diagnostic or treatment deficiencies.

This study is designed to determine the number of reattenders, and the reasons for reattendance. Specific areas in which diagnostic and communication difficulties are frequently found will be identified and attneticit focussed on junior doctor training in this area. In the case of visits which are thought to be avoidable, the associated morbidity will be assessed. Finally, protocols will be designed for the management of rettenders who are thought to be at risk of significant morbidity.

Method.

From departmental records of August, October and December 1993, the records of all patients who reattend within a week of the original presentation will be reviewed. The reason for reattendance will be sought and divided into the following categories of problems:

diagnosis, management, communication with patient, communication with other agencies.

Scheduled reattendances will also be examined for the appropriateness of the retum visit, adequacy of the original consultation and written documentation.

Reattendance rates will be compared between August and the following months to identify the effect of experience on the incidence of each of these types of problem.

Following the study, a regular audit system will be set up using the results of the study to improve availability of information regarding quality of care.

\section{A25 Retrospective Evaluation of Changes in Cardiac Resuscitation over 2} years in a large Accident and Emergency Department.

V. Gautam, C. Mann, T. Stumpf, J. Heyworth

York House, Queen Alexandra Hospital, Cosham

Between 1991 and 1993 there has been a substantial increase in the uptake of Advance Life Support Training and the avallability of paramedics in the front line ambulances. The study was designed to evaluate the effect of these two changes on the cardic resuscitation workload and outcome at a large

Three consecutive months' record of cardiac resuscitation from 1991 and 1993 was analysed for survival, the condition of the patient at the time of presentation to ABD and the progress of life support in the department.

Early results Indicate a statistically significant improvement in the survival 1n the group from 1993. There also appears to be a change in the condition
of the patient on arrival in AED, indicating the need to focus the resuscitation training differently for AED staff.

Full data from the study will be presented in the paper together with prellminary results of a comparison of outcome from resuscitation in the AED led Life Support, Paramedics, Cardiac Resuscitation, Outcome, Training 


\section{A\&E DBPARTMBNTAL DEATHS}

K. Jones, G. Hughes \& M. Clancy

BRISTOI. ROYAI. INFIRMARY

Over a 3 year period (1991 to 1993) the notes and post-mortem reports of al1 patjents on whom resuscilation was attempled were revjewed. Cases were categorised into expccted post-mortem indings and uncxpectad findings. The uncxpected deaths wcre deaths were cjassificd on the basis that cither:

1. patjent oulcome could have been altered in the light of the post-moricm findings or

2. the post-morlem findings would not have altered potient oulcome but should have been guspecied or detccited.

RESULTS:

A total of 179 deaths were analysed. Ten were significant unexpecled cases (5 trauma. 2 abdominal aortic aneuryms. 2 other
and 1 cordiac). Four cases will be presented os illustrative examples.

DJSCUSSJON:

Th1s review has highlighted the educational benefit of post-mortem analysis. As a consequence wc now at.Lend all posito improved liajson with the pathologarts ant more dataied post-mortem reparts. Key elements of post-mortcms arc now being post-morlem reports. Key elemcnts of post-mortcms are
videod so that A\&E staff unable to attend may henefil.

A27 Pre-hospital Accident \& Emergency and Emergency Doctors - is there a need?

John Scout, Robert Cocks

'A \& E Dept, Hammersmith Hospital, Du Cane Road, London W12 OHS

Objective - To assess the need for Accident and Emergency doctors in Pre-Hospital care.

Design - Prospective Study - with 200 cases.

Setting - Central and West London.

Main Outcome Measures - Interventions beyond paramedic skills,

Paramedic requested calls, Response times.

Results:- $36 \%$ of calls resulted in interventions beyond the skills of the paramedic. $15 \%$ of attendances requested by a paramedic on scene. The first person on scene in $60 \%$ of the calls was the Accident and Emergency doctor.

Conclusion:- Accident and Emergency doctors have a role in prehospital care.
A28

Better Pre-Hospital Care in the United Kinedom, Lessons from Abroad
Fiona E. Lecky
Department of Emergency Medicine, Hope Hospital, Salford M6 8HD

Objective: To determine whether current systems of pre-hospital care used in other countries, demonstrate ways in which the Unitod Kingdom system could be improved.

Design: Descriptive Study; non-participant observation of systems of pre-hospital care by a trainoe in Aocident and Emergency Medicine.

Settines: Ambulance services of Washingtoa DC, Maryland State, and Johannesburg. SAMU (Service D'Aide Modicale Urgente) of Paris. Brussels and Leuven.

Subjects: Each system was observed in operation over a period of three to five days.

Ressults: Differences were found between one or more of the "foreign" systems, and Unitod Kingdom prothocpital care, in four areas:

1. Dispotch of Advanced Life Suppert (ALS) Providers: Triage of emergency calls for "an ambulances" is ectioved in the SAMU de Paris control centre, by medical telephonists and anecesthesiologists. In 1992, this triage system ideatifiod that only five percent of calls required the dispatch of ALS provider teams.

2. Vehicles: Paramedics travelling in rapid response cars, such as Ford sierras used by the Johanneaburg city ambulance service, can answer on average twenty percent more calls per shif than paramodics travelling solely in ambulances. 3. Parnmedic training: South African paramedics are trained for three years and recruitod as college leavers. The high esteem that they are held in by the Johannesburg trauma surgeons, suggests that appropriate seloction and training of paramodics can deliver good quality pro-bospital care.

4. Medical involvement in presthespital care: A higher level of medical involvement, than that which curreodly occurn in the UK, is present in all six "foreign" systems observed. This is schievod by more sophisticated pro-boepien communication networks, allowing pre-hospital care providers to discuss patient management with roceiving physiciens. In the European systems, doctors were the main probospital ALS providers. However in the U.S. and Johennesturn paramedics provide most ALS in the pro-bospital setting.

Conclusion: All the systems observed have at least one feature that if adopted in the UK, could improve patien management in the pre-hospital setting. In particular, triaged dispatch and rapid response cars would allow UK paramodics to be used more efficienlly and effectively.

Pre-hospital care; international comparisons

Intraosseous (IO) infusion is an access alternative in selected patients. While this route is used mostly in children, experience in adolescents and adults is accumulating. We developed an IO needle (SurFast, cook critical care, Bloomington, IN) to reduce extravasation, allow access through the harder cortex of adolescents and adults, and improve anchoring. We report our experience in twenty-seven patients.

Results: Twenty-eight of 32 insertion attempts were successful (87.5\%). All second attempts were successful. Insertion time averaged < one minute. Patients were age two weeks to sixty years. Flow rates averaged $1-2 \mathrm{ml} / \mathrm{kg} / \mathrm{min}$ in infants and children. In adults, rates averaged $150-200 \mathrm{ml} / \mathrm{min}$ with pressure. The insertion site was the proximal tibia in all but one case (medial malleolus). The only complication was minimal extravasation in two instances, both after extended pressure infusion. Problems included inability to verify needle placement in one case and difficulty removing the insertion handle. No needles were displaced from the insertion site.

Discussion: We report our experience with a threaded Io needle. It was successfully placed $87.5 \%$ of the time and achieved the design goals. The handle was modified for easy removal. Further study in a variety of emergency settings is warranted. 
$\mathbf{A 3 0}$

\section{CRICOTHYROIDOTOMY IN THE ACCIDENT \& EMERGENCY DEPT}

\section{Carew-McColl}

\section{A\&E Dept., Royal Preston Hospital, Fulwood, PRESTON Lancs.}

In an 18 month period 5 emergency cricothyroidotomies were performed within or around the Accident \& Emergency Department at the Royal Preston Hospital. The indications for each are briefly described. There were no short or later adverse consequences related to the procedure.

When patients attend with trauma induced upper airway problems, most Casualty Officers will either temporise with conservative measures or try to persuade an Anaesthetist to intubate the patient - and this will generally mean paralysing and ventilating them. Neither of these treatments may be appropriate in the patients circumstances - the first leaving the patient vulnerable and the second possibly aggravating the situation and/or reducing an orientated and responsive patient to a dependent one on an Intensive Care Unit. It is probably not reasonable to expect an inexperienced SHO to perform such a procedure but he or she should be expected to identify that there is a problem and bear in mind that cricothyroidotomy may be the answer. It is essential that a larger receiving centre has, inmediately available, someone of sufficient seniority and competence to be able to perform this procedure quickly and efficiently as some of these patients have run out of debating time. We invariably use a size 6 or 7 cuffed tracheotomy tube as the one usual major concern for the patient is bleeding down the trachea from above

Therefore we instituted the use of whole bowel irrigation (WBI) in severely poisoned patients ( $n=27$ ), estimated to be absorbing at admission. The spectrum of offending substances extended from pesticides and herbicides $(n=3)$, cocain body stuffer $(n=1)$, slow-release formula ( $n=2)$, to a broad mixture of common medicaments $(n=21)$.

WBI was deemed essential for survival in 3 patients, and able to reduce toxicity and morbidity in 11 patients. An influence on outcome (mortality and length of stay in ICU) was debatable or not existing for 13 patients. No complications attributable to WBI were identified.

Optimization of WBI included the use of additional drugs, rate and amount of intestinal fluid given, and development of accompanying nursing procedures.

WBI seems to be a hithero underused technique in treatment of severe peroral poisoning. Further experience is needed to define indications, risk and benefit of the procedure.

A32

BIOCHEMICAL MARKERS IN DIAGNOSIS OF ACUTE MYOCARDIAL INFARCTION IN ARE

Huggon AM, Chambers J, Nayeem N, Crook M, Tutt P. Swaminathan S

Department of Accident and Emergency, Guys Hospital, London. U.K

Venous blood from patients presenting to $A$ \& $E$ with chest pain or a history suggestive of myocardial infarction (MI) was analysed. CPK. CKMB activity, CKMB mass, troponin $T$ and myoglobin were measured. A consunant cardiologist made a retrospective clinical diagnosis based on the clinical notes, ECGs and CPK results but with no knowledge of CKMB mass, troponin T or myoglobin results

Over 500 patients have been entered into the study. Currently 130 diagnoses are known. 24 patients so far have been classified clinically as " definite MI". 22 of these presented within 24 hours of the onset of pain.

CPK and CKMB mass were more sensitive tests than troponin $T$ and myoglobin both overall and in the subgroup of Mis presenting at 6 hours or less from the onset of pain.

Diagnostic sensitivitios of cardiac marken

\begin{tabular}{|l|l|l|l|l|l|l|}
\hline $\begin{array}{l}\text { Time from } \\
\text { pain onset }\end{array}$ & No patients & Troponin T & Myoglobin & Total CPK & $\begin{array}{l}\text { CKMB } \\
\text { Activity }\end{array}$ & CKMB Mass \\
\hline 4h or less & 16 & $3 / 16(19 \%)$ & $3 / 16(19 \%)$ & $6 / 15(40 \%)$ & $2 / 15(13 \%)$ & $7 / 14(50 \%)$ \\
\hline gh or less & 18 & $5 / 18(28 \%)$ & $5 / 18(28 \%)$ & $8 / 17(47 \%)$ & $4 / 17(24 \%)$ & $8 / 15(53 \%)$ \\
\hline All Mls & 24 & $10 / 24(42 \%)$ & $9 / 23(39 \%)$ & $14 / 23(61 \%)$ & $6 / 21(29 \%)$ & $12 / 20(60 \%)$ \\
\hline
\end{tabular}

Iable showina false positive tests

\begin{tabular}{|l|l|l|l|l|l|}
\hline & Troponin T & Myoglobin & Total CPK & CKMB Activity & CKMB Mass \\
\hline False positives & $5 / 19(26 \%)$ & $9 / 22(41 \%)$ & $13 / 32(41 \%)$ & $4 / 13(31 \%)$ & $6 / 25(24 \%)$ \\
\hline
\end{tabular}

The results so far in this study do not support the use of troponin $T$ or myoglobin in the earty diagnosis of MI in A\&E

Myocardial infarction, CPK, troponin T, Myoglobin, CKMB 
Track B

Initial emphasis was placed on the in-patient specialties with Diagnostic Related Groups, a surrogate for length of stay, being modified to reflect the cost of procedures in British Hospitals and called Health Care Resource Groups or HRGs. Orthopaedics will be the first Specialty to report its activity in HRGs from April 1994.

Work on developing a set of HRGs for Emergency Medicine has been in hand in Colchester since 1990. A Cost Model was prepared and a study of over 3,000 micro-costed episodes has been statistically analysed.

The Method of Disposal was identified as the most robust and user friendly casemix measure. A validation project is in hand at Whipps Cross. The National Casemix Office expects specialty returns from April 1995. What are the problems / opportunities with this approach? How ready is the specialty to respond in this time frame? What are the contracting and funding implications for the specialty? Should HRGs carry a Government Health Warning for the specialty?

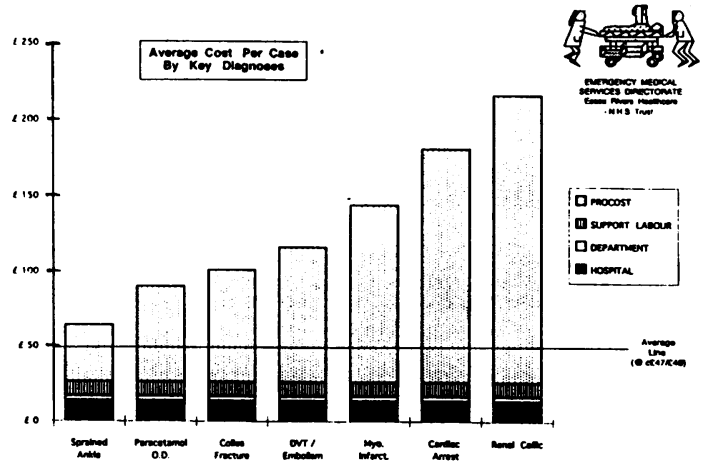

Resource Management, Ambulatory Care, Casemix. HRG, Emergency Medicine.

324 The Accident and Emergency Department

A Resource for Primary Accident Prevention as well as Tertiary Data Collection

Dowd, Hugo D. : Dorkin. Trevor. : Jackson., Hugh

Accident \& Emergency Department, Newcastle General Hospital.

Objective - The authors set about to identify the demographics of smoke detector possession and the effect of promoting fire prevention in the Accident \& Emergency setting.

Design - Case control study by questionnaire completed by carer of child

Setting - A large A \& E department in Newcastle upon Tyne.

Subjects - 464 children who attended the A\&E dept of NGH between 1 to 31

December 1993

The cases comprised of 290 homes with smokers. The controls were 174 homes

without a smoker resident.

Main outcome measures - Ownership, positioning and maintenance of detectors in

the home cost estimation of detector and any history of house fire. Application for

free smoke detector.

Results - 2 out 3 homes had a detector. Non-smokers were more likely to protect their home and family from fire with a detector than smokers. (relative risk 2.91 $(95 \%$ confidence interval 1.90 to 4.46$) p=0.1)$ and less likely to be involved in house fires.

Home owners who do not smoke are more likely to have a detector (relative risk 4.0 (95\% confidence interval 1.8 to 8.3 ) $p=0.0003$ )

There was no significant difference between the two groups who were yet to get a detector.

Smokers and non-smokers displayed the same behaviour re. use and maintenance of their smoke detectors. the number of persons resident. However non-smokers were three times more likely to get a detector after a house fire than smokers. Cost was not the reason for not having a detector. The response rate 10 the smoke detector offer was 10 himes greater than previously recorded $\{0.6 \%$ after postal offer to 16.000 homes throughout 1993.

postal offer to 16.000 homes throughout 1993.\} Conclusion - Data collection in A\&E can provide useful information and can be used to identify resources for injury prevention. Furthermore, opportunistic targeting in an A\&E setting is a more effective use of local resources than methods currently employed.
SHO HANDBOOKIN A\&E - ARE THEY REALLY EFFECTIVE? ANNE E ROBINSON GLENNYS PARSELL

ACCIDENT AND EMERGENCY DEPARTMENT WARRINGTON HOSPITAL NHS TRUST WARRINGTON

Since 1st October 1992, the Accident and Emergency Department at Warrington Hospital has been involved in a hospital-wide project which has as its aim 'the improvement of SHO education and training'.

An educational structure has been developed and implemented in the Accident and Emergency Department at Warrington Hospital. This has included the development of an 'SHO Handbook and Training Record', based on principles of adult learning.

The structure was introduced into the Accident and Emergency Department on 1st August 1993. SHOs were interviewed on the educational structure and the handbook after two months and completed a questionnaire at the end of their post.

The paper describes the process of implementation and evaluation of the educational structure and examines its impact on the SHOs and senior staff in Accident and Emergency. We discuss how the evaluation findings have been used to develop the handbook and direct further change in education and training in the Department.
ABSTRACT: STOCHASTIC MODELLING IN THE MANAGEMENT OF A \& E SERVICES

Stochastic modelling allows complex systems and interactions to be evaluated and for decision making to be optimised.

An information system is described which is currently in use in Chesterfield Accident \& Emergency Department and which has been developed to present information suitable for stochastic modelling. The model produced allows for decisions to be made in real time and using real data (i.e. not a simulation). I believe the features of this model of being interactive in real time and using real data make it unique in the U.K. (and possibly in the English-speaking world).

The system, its uses and potential are discussed. The presentation is supported by a demonstration of the use of the model in optimising queuc management, prioritisation of patients and waiting times.

W. D. Malone

Chesterfield \& North Derbyshire Royal Hospital 
Lightning Injuries -- 1994 lipdate

Lightning is a major weather related cause of injuries and deaths. Recently, there have been new developments in lightning research that Emergency Department physicians should know. This presentation will focus on three areas of lightning research.

1. New technologies in lightning detection. There are now two types of lightning detectors available to golf course and other recreational sport directors. Magnetic directional finders detect the instantaneous field signal associated with a lightning flash. These signals are specific for lightning strikes. Another new device can detect a change in light intensity in clouds during the daytime. The numbers of injuries should be reduced with available detection and warning systems. $\therefore$

2. With the advent of MRI technology, the clinician can often identify the site and type of lesion so that appropriate treatment can be given. MRI's have been helpful in identifying cerebral infarction, cerebellar degeneration, hypoxic encephalopathy, etc.

3. Lightning injuries are under-reported. Most estimates are based on media reports. In the past year, members of the Lightning Data Center and NOAA, have collected data from sources (Colorado Hospital Association, Colorado death certificate registry. etc.) and found that lightning injuries in Colorado are underreported by $30 \mathrm{x}$.

B30

Falls in the Elderly: Health of the Nation and the Accident and Emergency department. MR SEAN J. McGOVERN.

ROYAL VICTORIA HOSPITAL, A/E DEPARTMENT, FALLS RD. BELFAST BTI2

Objective; To determine adcquacy of assessment of the elderly paticnt who attend the accident and emergency department after a fall and the role of immediate occupational therapy (O.T.) assessment. Design; A prospective study with historical controls. A questionnaire was used prospectivcly to assess the need for occupational therapy Setting: Accident and emergency department. Belfast City Hospital. Patients, 190 elderly patients ( agod > 70 years ) attending the department between September 1993 and January 1994 as a result of a fall. Main outcome measures: The adequacy of assessment of the patients in terms of history of the fall, physical, mental, functional and social assessments performed by the accident and emergency doctor. The patients that could bencfit from immediatc occupational therapy assessment. Results; 100 (23\%) over 70 in the retrospoctive study werc admitted to the deparment. Adequate documented history of the fall was found in 22 ( $45 \%$ ) of the patients discharged and in 321 64\%) of those adnitted. Blood pressure was recorded in 44 cases 15 ( 30\%) who were discharged and 29 ( $58 \%$ ) of admitted. Social assessment was carried out in 8 (16\%) of those discharged and 17 ( $34 \%$ ) of those admitted. Activities of daily living were recorded in $9 \%$ of all cases. Mental state assessment was performod on $7 \%$. 9 ) patients were studied prospectively, 52(57\%) patients were discharged, O.T. assessment was requested in $38(6 \% \%)$ cases of those patients discharged using predetermined criteria. and intervention required in $29(76 \%)$ of thesc cases to improve mobility and independent function. Conc/usion: Assessment of elderly who fall is poor in the a/c department. Doctors concentrate on the injury sustained forgetting that offen a fall in the elderly is a marker for functional decline. A questionnaire does produce better assessments, when coupled with carly access to O.T. it may reduce accidents in the elderly so allowing the a/e department to assist in accident prevention as sct out in the Hcalth of the Nation Document.

Emergency department. Health of the Nation, Accident prevention, Falls, Elderly. Questionnairc.
B31 SUPERFICIAL HAHD BURNS TREATED IN GORETEX BAGS ALISTAIR FRASER-MOODIE AND MARK HENLEY

\section{DERBYSHIRE ROYAL INFIRMARY}

NOTTINGHAM CITY HOSPITAL
Abstract: Superficial hand burns treated in plastic gloves cause maceration to the unburnt skin, frequent leakage and discomfort. Goretex is a polytetrafluoro-ethylene. It is water permeable, but a barrier to airborne particles including bacteria (Goretex 1983). When laminated to fabric, it is strong. So could problems with plastic bags be prevented by using Goretex?

48 patients with a total of 63 superficial hand burns were entered in a trial. They were randomly allocated to treatment with plastic gloves or Goretex bags after applying Flamazine and followed up.
31 HAND BURNS TREATED 32 HAND BURMS TREATED
IN PLASTIC Bags IN GORETEX bags

(Aetiology and size of burns similar)

More painful generally

(statistically significant) (statistically significant)

More painful at dressing Fewer problems eating, going to

(statistically significant) tollet or dressing.

Slipped of more

(statistically significant)

Leaked more

No patients worked

Fewer hospital attendances

4 patients worked

Healing times identical

Goretex bags used here for the very first time in an Emergency department are shown to be superior to plastic bags in the treatment of superficial hand burns. But each Goretex bag costs E 15 to make, so can your trust afford them?

Goretex - plastic - pain - maceration - slipping of . 


\section{Track C}

EMERGENCY DEPARTMENT EVALUATION OF NON-TRAUMATIC, AFEBRILE CONFUSION IN GERIATRIC PATIENTS

Study objective: To evaluate the use of blood work. head Cr scans and chest $x$-rays in, and devise an algorithm for, the testing of elderiy ( $>65$ years) patients presenting with afebrile, non-traumatic acute ( $<1$ month) confusion without focal neurologic signs.

Design: Retrospective review of Emergency Department (ED) medical records of the above described patients from January 1990 through January 1993. Setting: Large tertiary referral ED with 65.000 annual patient visits. Results: One hundred ninety-nine patients were identified as meeting inclusion criteria. Forty-six were dismissed from the EO. One hundred fifty-three were admitted to the hospital. No blood tests other than electrolytes. creatinine and complete blood count were required in the decision to admit or dismiss the patient from the Ėं. Head CT scans were necessary for patients with a remote history of falls, headache, diffculty finding words and metastatic cancer. Chest $x$-rays were only useful in patients with chest symptoms or an elevated white blood count. A patient evaluation algorithm based on these results was then successfully applied to a similar group of patients; substantial cost savings were obtained without missing significant illness.

Conclusion: Using retrospective data aralysis. geriatic assessemnt algorithms can be devised to assist emergency physicians perform more efficient and cost-effective evaluations of certain groups of patients.

Nbstract :

Introduction post Traumatic Stress Disorder (PTSD) can be caused by any traumatic event. It is more common after disaster related trauma like train crash, bomb blast, earthquakes and other disasters. Bomb blast victims are particularly prone to have PTSD. Most studies on the subject are retrospective. None have documented the level of Acute PTSD and its comparison with Chronic PTSD and thus there is no accuracy in documentation of benefits of various forms of treatments. Study objectives. To assess the level of Acute PTSD ( 6 months post incident), to assess the level of Chronic PTSD ( $>6$ months post incident), and to assess the benefits of structured early counselling in bomb blast victims.

Desiom/type of Participants:- A prospective study of 31 victims involved in the Bishopsgate Bomb Blast in the City of London on 24 th April 1993.

Setting Inner city teaching hospital in London

Method All 31 victims received immediate treatment at the hospital and subsequently reviewed within a week. At the Major Incident Follow up clinic victims were evaluated for stress and early counselling was given along with physical injuries management.. Further counselling and follow up was arranged through professional counsellors. Acute and Chronic PTSD was evaluated using criterion laid by American Psychiatric Association manual (DSM III R).

Besults Acute PTSD at 1 month was $78 \%(n=24)$ and Chronic PTSD at 7 months was $228(n=7)$. Only 2 victims required psychiatric attention for suicidal depression. The results clearly show a high level of Acute stress ( this has not been reported before due to retrospective nature of previous studies) and confirms the value of structured early counselling starting within a week of the incident.

\section{C19 The problems associated with relatives watching resuscitation Mr Michael R. Whitlock FRCS, Sarah Adams}

Barnet General Hospital, Herts

Previous work has suggested that some people would like to watch the resuscitation of close friends or relatives, but few hospitals actually encourage it. There is a special problem for doctors who need to resuscitate outside the hospital or in their role as medical officer at e.g. sporting events. This paper gives the personal view of one person who had to insist on watching her brother who, unfortunately, died. A survey of $\mathbf{5 0}$ families whose young relative died suddenly from an accident confirms the previous view that even though some did not want to be present they all would like to be given the choice. Young adults, especially, would like to be present.

The special problems associated with resuscitation outside the hospital setting are discussed and recommendations as to how it should be planned before the event made.

The inadequacies of bereavement counselling services for relatives of young people who die from accidents are highlighted. This has resulted in a new service being set up which will offer similar facilities to that of other organisations such as $\mathrm{Cot}$ Death Association and TACT.

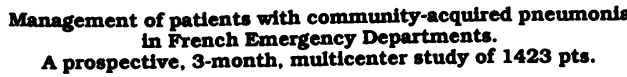

Study purpose. To identify the outcome of patients with community acquired pneumonia (CAP) seeking hospital care through the emergency department (ED).

Design. All consecutive pts. 1) with respiratory symptoms + temperature $\geq 38^{\circ} \mathrm{C}+$ recent anomalies on chest X-ray (CXR). 2) age $\geq 15$ years, and 3 living in the community for $\geq 7$ days at time of onset. were enrolled. Within 48-72 $\mathrm{h}$, they were either excluded (if a diagnosis other than CAP was established). or included into 3 CAP classes : defhnte. probable, doubtul. Management modalities before. during and after ED-vsit and follow-up were collected. A clinical s

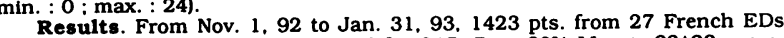

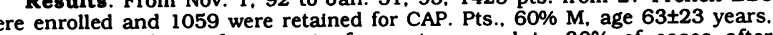
consulted $9 \pm 4$ days after onset of symptoms and in $30 \%$ of cases after antibiotics (AB) were prescribed. In the ED, they received empirical $A B(60 \%)$ before admission to a medical ward $(80 \%)$. ICU (13\%) or discharge. sometimes after an observation period in the ED-unit (5\%) (Table) : $18(2 \%)$ were exclusively managed in the ED. Main admission motives were severity of CAP $(35 \%)$ and medical history $(20 \%)$. During hospital stay, initial AB therapy was modified in $40 \%$.

\begin{tabular}{|c|c|c|c|c|c|}
\hline $\begin{array}{l}\text { Age (years: } \bar{x} \pm S T D) \\
\text { CXR involvement: } \\
\text { - uni/bilat (\%) } \\
-1 / 2 / 23 \text { lobes }(\%) \\
\text { CAP definite/probable (\%) } \\
\text { SED Score }(\bar{x} \pm \text { STD) } \\
\text { Hosp/ED stay (days: } \bar{x} \pm \text { STD) } \\
\text { Recovery/death (\%) } \\
\text { Lost to follow-up (\%) }\end{array}$ & \begin{tabular}{|c|c} 
All \\
(n=1059) \\
$63 \pm 23$ \\
\\
$80 / 20$ \\
$66 / 24 / 10$ \\
$26 / 67$ \\
$6 \pm 3$ \\
$13 \pm 12$ \\
$83 / 13$ \\
4
\end{tabular} & 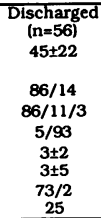 & \begin{tabular}{|c|} 
Medical ward \\
(n=845) \\
$64 \pm 22$ \\
\\
$83 / 17$ \\
$70 / 22 / 8$ \\
$24 / 69$ \\
$6 \pm 3$ \\
$13 \pm 11$ \\
$87 / 10$ \\
3
\end{tabular} & $\begin{array}{c}\text { ICU } \\
(n=140) \\
58 \pm 19 \\
\\
56 / 44 \\
40 / 40 / 20 \\
50 / 45 \\
8 \pm 3 \\
14 \pm 16 \\
64 / 33 \\
3 \\
\end{array}$ & \begin{tabular}{|c|}
$p$ \\
$10^{-4}$ \\
$10^{-5}$ \\
$10^{-5}$ \\
$10^{-5}$ \\
$10^{-4}$ \\
0.006 \\
$10^{-5}$
\end{tabular} \\
\hline
\end{tabular}

Seven micro-organisms were found in over

peume adequate. 2) Improving CAP diagnosis and AB therapy in ED is our next objective. 
Utility of observation beds in the emergency department of a 022 tertiary care hospital In India

Results: During the study period, a total of $1,15,916$ patients attended the ED of which, 11,130 patients (9.6\%) were observed in OR. There were 6,510 males and 4,620 females. The age range was $1-94$ years $(44.2 \pm 17.3)$. The period of sbservation ranged from 0.25 hours to 27.6 hours (mean $=7.74$ hours). The medical and surgical emergencies constituted 9,201 and 1,929 patients respectively. Of the patients observed in $\mathrm{OR}, 1,244$ patients $(11.2 \%)$ were admitted to the hospital and 1,126 patients $(10.1 \%)$ were referred to other hospitals due to non-availability of beds. of 8,734 patients $(78.5 \%)$ who were discharged after treatment, only 24 patients revisited ED within 72 hours of discharge for their original problems. Three patients out of 11,130 died during the period of observation. Details of various emergencies with respect to their number, duration of stay and disposition are shown below:

\begin{tabular}{|c|c|c|c|c|c|c|c|}
\hline \multirow{2}{*}{$\begin{array}{l}\text { Clioical Diagoosis/i } \\
\text { Chiel cosplaiot }\end{array}$} & \multirow{2}{*}{ No. of patieotsid } & \multirow{2}{*}{$\begin{array}{l}\text { Duratioo of tayy } \\
\text { (Heas) }\end{array}$} & \multicolumn{5}{|c|}{ Fioal dispositioo } \\
\hline & & & Adnitted & Discharged & Tother hospitals! & Died & GAMA \\
\hline $\begin{array}{l}\mathrm{Broco} \\
\mathrm{C} O \mathrm{O}\end{array}$ & 1,831 & rв & $120(8.72)$ & $1.031(83.42)$ & 3671 & $1(0.02 \pi)$ & $1210.25 \%$ \\
\hline Chest p & 1,16911 & 6.1 hours & $176(12.08)$ & $1,013(71.02)$ & $213(16.52)$ & $1(0.072)$ & 610.412 \\
\hline CHF & 1,0471 & bours & 2021 & 737 & 106 & $0(0.002)$ & 210.192 \\
\hline Abdonioa & 91 & r6 & $101(11.17)$ & $744(81.52)$ & $68(7.4)$ & $0(0.00 x)$ & 010.002 \\
\hline Castroeoteritis & $120(3.82)$ & 7.1 hours & $52(12.12)$ & $316(75.2 x)$ & 51112 & $1(0.248)$ & 010.002 \\
\hline Acce & ) & 3.8 & $11(5.02)$ & $256(90.12)$ & $11(3.9 \pi)$ & $0(0.002)$ & 110.352 \\
\hline Trauna & $218(2.25)$ & 9.8 hours & $16(18.62)$ & 188 & 11 & $0(0.00 x)$ & 010.002 \\
\hline Poisooide & 11 & 8 hours & $7(1.9 x)$ & $121(84.08)$ & $15(10.42)$ & $0(0.002)$ & $110.70 x$ \\
\hline Miscellabeous & $1,776(16.02)$ & 5.5 hours & $226(12.7 x)$ & $1,298 \quad(73.17)$ & $251(111.12)$ & $0(0.008)$ & $110.05 x$ \\
\hline
\end{tabular}

Conclusion: An observation room in the ED is safe in treating acutely ill patients and is effective in reducing substantially the number of patients requiring admission to the hospital
REMOTE SURVEILLANCE OF EMERGENCY DEPARTMENT PATIENTS BACKGROUND: Unanticipated deterioration of non-ambulatory patients transported out of the ED for radiologie or other studies is a common problem. EDs lack sufficient staff to accompany all patients and those available in radiology departments are not trained to assume patient care. HYPOTHESIS: Employment of modern surveillance and monitoring equipment could permit ED personnel to observe and maintain contact with patients remotely.

METHODS: Technical feasibility of assembling a surveillance system was established by employment of commercially available materials and equipment. Operational objectives of the system included audio contact, parametric alarms for pulse and blood pressure, and an installed video camera system. A two-step ED response hierarchy was established. RESULTS: The system employs wall-mounted video cameras. Two way audio equipment, a cardiac monitor, and a portable blood pressure monitor are mounted on the gurney. The receiving terminal in the ED can observe the patient directly or be prompted to do so by timers and alarms. pulse and blood pressure can be observed continuously and assistance rendered if needed.

CONCLUSIONS; Some patients must have constant staff attendance when in the radiology suite. others may be observed remotely and more safely using this system. 
Track D

A new device to reduce needlestick injuries following IV cannulation J Watters, R MacCallum, S Maurice, C Robertson

Department of Accident and Emergency Medicine, Royal Infirmary, Edinburgh

\section{Obiectives}

To evaluate a novel cannula design (Safelon ${ }^{\text {Th}}$, Ohmeda) in relation to the potential reduction of risk of needlestick injuries.

Study design

Prospective study of IV cannulation. 18,20 and 22 gauge study cannulae were inserted according to clinical indication. The site, success rate, incidence of blood spillage, ease of insertion and needle protection were documented.

Setting

University teaching hospital Accident and Emergency Department.

Patients and methods

214 consecutive IV cannulations performed by the 4 members of the study team

Results

Sites of insertion included the dorsum of hand, forearm and anticubital fossa. There was an even distribution of site and side of insertion. First time insertion was successful in 203/214 cases (95\%). Blood spillage at separation of needle from cannula occurred in only $5 \%$ of cases. The ease of insertion was easier or equal to normal Venflon $(1)$ cannula insertion in $93 \%$. The retracted cannula needle was fully protected in $210(98 \%)$ of cases. In 3 cases the needle was unprotected because of operator technique error. There were no reported needlestick injuries.

Discussion and Conclusions

Needlestick injuries are common in A\&E Departments, and are associated with well recognised risks of disease transmission, especially for the Hepatitis B, C and Human Immunodeficiency viruses. The Safelon TM cannula is a novel and effective design which protects staff from the removed cannula needle. It represents a major improvement in user protection against needlestick injuries. The cannula is as easy to use as the normal Venflon $\otimes$ cannula. In addition to reducing the potential of needlestick injuries, we found that it also reduces the risk of blood spillage during the procedure.

Needlestick injuries and IV cannulation

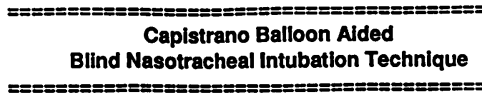

The Capistrano Balloon device consists of a balloon attached to a standard $15 / 22 \mathrm{~mm}$ fitting that easily snaps on and off to the proximal or external end of a pediatric or adult size endotracheal tube (ETT).

The usual technique of nasotracheal intubation is utilized, that is positioning the patient in the sniffing position. A well lubricated and appropriate tube for the patient size is selected. At this point the Capistrano Balloon device is attached to the proximal end of the tube. The ETI with the attached device is inserted into the selected nasal opening and passed through the nasopharynx, oropharynx, and hypopharynx. During the process the operator will notice some balloon fluttering (distention/collapse) with respiration. With each collapse of the balloon, it signals inspiration which physiologically coincides with the opening of the epiglottis and vocal cords. So as the balloon collapses the tube is inserted epiglottis and vocal cords. So as the balloon collapses the tube is inserted
further down through the vocal cords (VC). Once passed the VC, the operator will notice some increase in balloon fluttering which is rhythmic with the patient's respiration. Rapidly snap off the Capistrano Balloon device and ventilate the patient with the appropriate chosen mode.

The major advantage of using the Capistrano Balloon device, aside from it being a good visual aid to insertion and verification of ETT location, is less aerosol exposure to patient's secretions. The operator doesn't have to listen with his ears for airflow or expose his skin surface to detect air movement, hence no dependence on the operator's hearing acuity or tactile sensation.
"Comparison of Staples and Sutures for Cardiorraphy in Traumatic Cardiac Puncture"

Rapid thoracotomy and cardiorraphy is the best option for resuscitation of patients with penetrating cardiac trauma who deteriorate. Cardiac lacerations have usually required repair with non-absorbable sutures and pledgets. A recent report describes the use of a skin stapling device for repair of cardiac wounds. We hypothesize that the use of a skin stapling device for emergency cardiorraphy is faster, easier, and as effective as suturing in the hands of emergency physicians. An animal model, case control study was developed to directly compare the utility of these techniques by emergency physicians. Canine subjects, weighing at least $.20 \mathrm{~kg}$, were anesthetized and randomized to either a suture repair group or a staple repair group. A standardized right ventricular laceration was made. Physicians with similar prior experience were timed while repairing a laceration by each of the above techniques. Results showed cardiorraphy with a skin stapling device was significantly faster with.a mean repair time of 17.7 seconds, ( $N=17$, std dev: 10.4), when compared to suturing with pledgets which required a mean repair time of 199.6 seconds. ( $N=14$, std dev: 52). Blood loss was negligible with either technique and we found no discemible inter-operator difference.

All animals were observed for a period to grossly evaluate blood loss and competence of repair. No appreciable differences in blood loss or stability of repair were noted during this period. We conclude that cardiorraphy by stapling is more expedient, simpler to perform and equally efficacious as traditional suturing when performed by relatively inexperienced operators.

THE SAFETY OF LOW LEVEL LASER THERAPY - A CLINICAL TRIAL ON FOREARM SKIN

REYNOLDS PA, HUGGON AM, BOYD EGC, DOVER R, KIRBY NG

DEPT A \& E, GUY'S HOSPITAL, LONDON BRIDGE, SE1 9RT

Low Level Laser Therapy (LLLT) has been advocated for over 25 years for pain relief and wound healing. The devices used are distinguished from the high power surgical lasers by their lack of thermal effects. However the scientific evidence of efficacy of LLLT is highly controversial. Moreover safety aspects of LLLT have received only cursory attention in most studies. Recently publicity has been given to low dose electromagnetic fields which may be linked to some childhood malignancies.

Before embarking on clinical trials of LLLT in an Accident \& Emergency environment, a safety investigation was carried out using a Gallium Arsenide laser $(904 \mathrm{~nm}$ near infra red). Following satisfactory results from in vitro and in vivo investigations ethical permission from UMDS for a Phase 1 type (double blind) trial was obtained. The dominant forearms of 25 healthy male volunteers were irradiated with either 0 (sham), 2, 4. or $8 \mathrm{Jicm}^{2}$ on three consecutive days. A small biopsy was taken under local anaesthesia from both the test and contralateral arms on the final day. These tissue specimens were processed for histology and immunocytochemistry with MIB1 autoantibody to detect cells in the cell cycle.

Subjective analysis did not show any thermal or other adverse effects. The histopathology of all specimens was within normal limits. However, there was a significant reduction in the nuclear labelling by MIB1 of the lasered arm compared to the control arm within the parameters tested $(P<0.05)$. This probably indicates that there was a reduction in proliferation of the treated compared to the control arm. However, a direct efiect on protein synthesis cannot be ruled out.

SAFETY, LOW LEVEL LASER THERAPY 


\section{D19 Resistance of Protective Clothing to Penetration by Chemicals}

I. H. Arthur, R. A. Cocks

A \& E Dept., Hammersmith Hospital, Du Cane Road, London W12 OHS

Recent UK guidelines for protective clothing for medical and ambulance staff attending (major) incidents specifies only the reflective performance of the garment.

Preliminary work has suggested that these garments do not even give short term protection against a variety of chemicals.

\section{PENETRATION PROTECTIVECLOTHING CHEMICALS}

D21

A CHALCTED STABBING INCIDENTS RESULTING FROM THE "INTIFADA"

Dr. Zvi Feigenberg, Yossi Cohen EMT-P, Yizhak Ben-Aharon EMT-P, Dr. Yaacov Adler, Magen David Adom in Israe

Knife stabbings by fanatic Arab nationalist terrorists, whose aim is to kill and sow fear and hysteria among the citizens of the large cities in Israe Has posed new problems and organizational challenges unknown before, to the systen of the E.M.S. in Israel (Magen David Adom).

A terrorist, usually armed with a long large knife, runs anok in the crowded streets of the city, stabbing indiscriminately many citizens. In Tel Aviv, in one incident - 16 stabbed, 2 killed \& 3 seriously injured; in Jaffa - 10 stabbed, $2 \mathrm{killed}$ and 4 seriously/critically wounded; in Jerusalem - 4 killed, 5 wounded, 1 moderately injured.

The injured are scattered in a radius of about 200 meters on several streets, with no eye contact between one location and the other, many contradictory and inaacurate reports reach the emergency dispatching center of MDA - 101. On location: tens of milling onlookers and later also police forces. When MDA ambulances and MICUS reach the scene, each force directs them to the wounded in their locality, as a result of which the injured are treated according to their geographic location and not according to the severity of their injuries. Knowledge of more seriously wounded in the area but not within eye contact reaches them only after long and precious time is wasted.

The use of lethal weapons - long sword-1ike knives - with the clear intention of killing, caused most severe injuries with a higher than usual average mortality in stabbings.

We wish to describe the events in these three incidents, the difficulties and organizational and treatment problems and the conclusions, methods and preparedness of MDA for future similar incidents.
D20 THE 'NEW CITY'/'DREAM CITY'CINEMA FIRE SATURDAY 26 FEBRUARY 1994 REPORT REGARDING THE INVOLVEMENT OF DA 18.

DA 18 - a Volkswagen Passat Estate acts as a rapid response accident unit based at the Hammersmith Hospital on a research and development basis and dispatched via central ambulance control at Waterloo. At least one doctor is carried on DA

On board were:-

$\begin{array}{ll}\text { John Scott } & \begin{array}{l}\text { Senior Registrar, Accident \& Emergency department, } \\ \text { Hammersmith Hospital }\end{array} \\ \text { Michael Duggen } & \text { A Paramedic Trainee, an employee of the LAS for } 18 \text { years. } \\ \text { Andre Baumann } & \begin{array}{l}\text { A Paramedic \& Firefighter from Germany, seconded to } \\ \text { Fulham Paramedic Training. }\end{array}\end{array}$

Peter Walker Resuscitation Training officer from Central Middlesex. Computer Simulation of pre-hospital care in major incidents. Comparison between two methodelories.

V̀ Gautam, R Snook.

York House, Queen Alexandra Hospital. Cosham.

Computer Simulation is a well recognised tool for planning and education.

Several methodologies (and technologies) are avallable of reality on a computer. The paper examines the options avallable and compares in the U.K. with a system dynamics

The actual stages to bullding the model and translating that for computers wil also be discussed.

Computer Simulation, Disaster Planning, Pre-Hospital Care, Modelling.

The overall on-scene time of the casualties was about 55-60 minutes, including their entrapment. The response of the LAS paramedics and DA 18 was swift and they resuscitated all the live casualties to a point where they could be evacuated to hospital. There is no doubt in my mind that if it were not for the skills of the LAS paramedics with the assistance of DA 18, all the casualties would have died on the street before arriving at the hospital.

The incident required an instantaneous medical response which did not permit the gold standard role of the medical incident officer. However, everyone tried as best they could in the circumstances to work to the protocol of a major incident procedure. The actions of those on scene allowed patients to arrive alive at the hospital.

DA 18 are in the process of acquiring Cambridge Triage labels and a medical incident officer tabard. In addition we are collating the telephone numbers and facilities of all the London hospitals, so that this information is available in the car.

It was impossible to get through to $\mathrm{UCH}$ on their switchboard number. The Hammersmith Hospital switchboard actually contacted UCH via the HEMS desk. Both UCH and St Bartholomews were asked to phone me on my portable phone via the Hammersmith Hospital switchboard.

I would like to take this opportunity to thank the LAS Paramedics for the exemplary actions. They were a credit to themselves and the LAS. In particular, Mr Richard Cocks, Michael Duggen and Richard Phelps, the ambulance incident officer, are to be commended for their actions. 


\title{
223 The Severely Injured who don't use Emergency Services
}

B. P. McNicholl, S. Lee

A \& E Dept., Royal Victoria Hospital, Grosvenor Road, Belfast

\begin{abstract}
In a one year study of major trauma (ISS $>15) 39$ of 239 patients (16\%) arrived in the Emergency department of the nearest hospital without using emergency services. Half of them (20 patients) required urgent surgery for life-threatening injuries compared to $22 \%$ of patients using emergency services $(44$ of $200, P<.01$ ). Nine operations were neurosurgical, eight were abdominal. Thirty one percent of all urgent surgery in Northem Ireland is expected to arrive in hospital in this fashion. Two patients were severely shocked, 14 had an abnormal Glasgow Coma Scale in the Emergency Department. Suspected reasons for not using emergency services were: underestimating the extent of injury and perception that private transport would be quicker.
\end{abstract}

A trauma system that bypasses hospitals must provide contingency plans for these patients. If not, because of diminished expertise in the bypassed hospitals they are put at risk. 